\title{
Flexural Tensile Strength of Concrete with Synthetic Fibers
}

\author{
Julia Blazy ${ }^{1, *(\mathbb{D})}$, Lukasz Drobiec ${ }^{1} \mathbb{D}$ and Paweł Wolka ${ }^{2}$ \\ 1 Faculty of Civil Engineering, Silesian University of Technology, Akademicka 5, 44-100 Gliwice, Poland; \\ lukasz.drobiec@polsl.pl \\ 2 Astra Technologia Betonu Sp. Z.O.O., 83-010 Straszyn, Poland; pawel@astra-polska.com \\ * Correspondence: julia.blazy@polsl.pl
}

check for

updates

Citation: Blazy, J.; Drobiec, Ł.; Wolka, P. Flexural Tensile Strength of Concrete with Synthetic Fibers.

Materials 2021, 14, 4428.

https://doi.org/10.3390/ma14164428

Academic Editor: Dario De Domenico

Received: 6 July 2021

Accepted: 5 August 2021

Published: 7 August 2021

Publisher's Note: MDPI stays neutral with regard to jurisdictional claims in published maps and institutional affiliations.

Copyright: (C) 2021 by the authors Licensee MDPI, Basel, Switzerland. This article is an open access article distributed under the terms and conditions of the Creative Commons Attribution (CC BY) license (https:/ / creativecommons.org/licenses/by/ $4.0 /)$.

\begin{abstract}
Fiber reinforcement is currently most often used in floors, railway sleepers, prefabricated structural elements such as slabs, beams and tanks, and in small architecture elements. Designing elements or structures made of fiber-reinforced concrete requires knowledge of its basic mechanical parameters. In the case of concretes with metallic fibers, the literature can find many tests and standard guidelines regarding compressive, flexural, tensile strength and fracture energy. The properties of concretes with non-metallic fibers are slightly less recognized, especially concretes with new types of polymer fibers. Additionally, the lack of standardized methods of testing concrete with polymer fibers make their application much more difficult. In the article, the possibility of using the EN 14651 standard to assess the flexural tensile strength of concrete with the addition of 2.0 and $3.0 \mathrm{~kg} / \mathrm{m}^{3}$ of synthetic fibers with different geometry and form was presented. There was a $5.5-13.5 \%$ increase in the flexural tensile strength depending on the mixture type. Moreover, in the case of fiber-reinforced concretes, the ductility was enhanced and the samples were characterized by significant residual flexural tensile strengths. Additionally, from the workability tests it was concluded that after the incorporation of fibers, the consistency class decreased by one, two or three. Nevertheless, the compressive strengths of concrete with and without fibers were very similar to each other, and varied from 58.05 to $61.31 \mathrm{MPa}$. Moreover, it was concluded that results obtained from three-point bending tests significantly differed from empirical formulas for the calculation of the flexural tensile strength of fiber-reinforced concretes with dispersed steel fibers present in the literature. As a result, the new formula determined by the authors was proposed for concrete with polymer fibers with a nominal fiber content $\leq 1.0 \%$ and slenderness of up to 200 . It must be mentioned that the formula gave a very good agreement with studies presented in different literature positions. In addition, an attempt was made to evaluate the strengths of tested mixes in accordance with the Model Code 2010. However, it occurred that the proposed fiber-reinforced concrete mixtures would not be able to replace traditional reinforcement in a form of steel bars. Furthermore, in uniaxial tensile tests, it was not possible to determine the $\sigma-\mathrm{w}$ graphs, and received results for maximum tensile strength did not show the clear influence of fibers incorporation on concrete. Then, the fracture energy enhancement (from about 16 to 22 times) and dependencies: crack mouth opening displacement-deflection; crack mouth opening displacement-crack tip opening displacement; and crack tip opening displacement-deflection were analyzed. Finally, the results from flexural tensile tests were compared with measurements of the surface displacement field obtained through the Digital Image Correlation technique. It was concluded that this technique can be successfully used to determine the crack mouth and crack tip opening displacements with very high accuracy.
\end{abstract}

Keywords: fiber-reinforced concrete; synthetic fibers; three-point bending test; crack mouth opening displacement; crack tip opening displacement; deflection; flexural tensile strength; toughness; uniaxial tensile test; Digital Image Correlation

\section{Introduction}

Fiber-reinforced concrete (FRC) is obtained by adding steel or non-metallic, e.g., synthetic fibers to the concrete mix. Metallic fibers are often used to significantly im- 
prove the mechanical properties of concrete, and when protection against cracks is very crucial. Therefore, steel fibers are used in the production of, among others, industrial floors [1,2], prefabricated constructional elements [3], prestressed elements [4,5] and linings of tunnels [6]. Moreover, the recent investigations on the application of FRC highlight the possibility of using them to manufacture railway sleepers $[7,8]$. Synthetic fibers also improve the properties of concrete, but to a lesser extent than steel fibers $[9,10]$. They are especially used because of their increased residual tensile strength, and thus better ductility compared to concrete without fibers [11]. Additionally, due to the fact that the fibers bridge cracks and their amount in concrete can be much higher than for steel fibers because their weight is smaller, they successively limit the width of cracks resulting from concrete shrinkage [12]. FRC with synthetic fibers is most often used in industrial floors, traffic surfaces, concrete slabs, tanks for liquids, elements of maritime infrastructure, culverts, as shotcrete and in elements of small architecture $[13,14]$. It is also noteworthy that synthetic fibers can be used in places exposed to water, as opposed to steel fibers, as it would not cause their corrosion [14]. The idea of durability enhancement due to the application of non-metallic reinforcement, which additionally limits the crack formations, is discussed in many studies, e.g., [15-18]. Sometimes both steel and synthetic fibers are added to the concrete, in order to obtain a mix with optimized properties and better performance [19].

The mechanical characteristics of FRC depend on the properties of the concrete matrix, but also on the material, dimensions $\left(l_{\mathrm{f}}\right.$-fiber length; $\mathrm{d}_{\mathrm{f}}$-fiber diameter), type and nominal volume content $\left(\mathrm{V}_{\mathrm{f}}\right)$ of fibers in the concrete. In addition, the bonding mechanism between the fiber and concrete also has an impact, i.e., whether the fibers are monofilament or fibrillated. Synthetic fibers can be divided into micro-and macrofibers. They are distinguished by their diameter: the microfibers have $d_{f}<30 \mathrm{~mm}$ and the macrofibers have $\mathrm{d}_{\mathrm{f}}>30 \mathrm{~mm}$ [20]. Their function is also different: microfibers prevent from microcracks occurring at the beginning of the concrete hardening process and increase tensile strength, and macrofibers often play an additional load-bearing function, protect against macrocracks and increase concrete ductility [4]. Furthermore, concrete is often formed with the addition of these two types of fibers to obtain a mixture that both replaces the traditional steel bar reinforcement and counteracts shrinkage [21].

The incorporation of synthetic fibers into the concrete mix influences its properties in various ways. Typically, the modulus of elasticity and compressive strength are similar to those for concrete without fibers. On the other hand, the fibers will have a very positive effect on ductility, toughness and freeze-thaw resistance, and will significantly reduce shrinkage, crack width and spalling during fire [14,22]. Properties such as abrasion resistance, tensile strength and flexural tensile strength will also be improved [14]. However, it should be noted that the influence of the addition of fiber in concrete largely depends on the workability of the concrete mix [23]. Namely, if it significantly deteriorates, the mechanical properties of concrete may be degraded, especially when its porosity, permeability and/or the amount of water absorbed will increase.

In order to test concrete in tension, the literature usually proposes two test methods: uniaxial tensile test (UTT) and three-point bending test (3PBT). However, UTT must be performed under very well-controlled conditions, using specialized equipment, without eccentricities, and on an ideal sample [24,25]. Otherwise, the test may be unstable and the results may be incorrect [25]. Moreover, UTT is very time-consuming, and depends on the interaction of the machine with the sample [24]. The easier and more popular test is 3PBT. Additionally, Model Code 2010 [26] and Technical Report 34 [27] state that in order to design FRC elements, it is necessary to determine the residual flexural tensile strength using 3PBT in accordance with EN 14651 [28].

Moreover, the Digital Image Correlation (DIC) technique is increasingly used to investigate the behavior of FRC. Babski et al. [29] analyzed the deformations of the ultrahigh-performance steel FRC samples and the crack propagation under tensile loading using the DIC system. In [30], fracture process zone development during the wedge-splitting test of concrete reinforced with recycled and industrial steel fibers applying the DIC system 
was examined. There are studies in which DIC was used to measure fracture parameters during 3PBT of plain concrete [31,32]. Experiments done by Manning et al. [33] focused on applying the DIC technique to study stress-strain behavior of prestressed channel girders reinforced with steel fibers. Additionally, in [34], slender steel FRC beam members under shear loading were monitored by the DIC system. As can be seen, many of the available studies focus on analyzing the concrete using the DIC system for plain concretes $[35,36]$, traditionally reinforced concretes by steel bars [35,37] or steel FRC, less on synthetic FRC. Namely, in [38], a study on residual compression behavior of polypropylene FRC subjected to moderate temperature was performed. On the other hand, Bertelsen et al. [39] focused on plastic shrinkage while testing samples with micro synthetic fibers. Finally, under 3PBT, the polyolefin FRC were investigated in [40] by Rucka et al., and in [41] by Bhosale and Prakash. Furthermore, one of the reasons for such big popularity of this optical technique is its non-destructive and non-contact character. Secondly, the technique allows recoding the damage evolution continuously and in real time. Finally, thanks to the DIC system, a large number of samples can be studied as the visualized surface deformation measurements are obtained quickly by successive post-processing of digital images.

Regarding the research significance, it must be noted that even though the EN 14651 standard [28] applies to concrete reinforced with metallic fiber, in the article it was proofed that the standard can be successively used when concrete is reinforced by synthetic fibers. In the article, three types of non-metallic fibers were added to concrete mix in amounts of 2.0 and $3.0 \mathrm{~kg} / \mathrm{m}^{3}$, for which the limit of proportionality and residual strengths were described. Furthermore, the proposition of new formula, despite the one presented in the EN 14651 standard [28] for metallic fibers, to describe the relationship between deflection and crack mouth opening displacement for synthetic fibers was introduced. Other dependencies such as crack mouth opening displacement-crack tip opening displacement and crack tip opening displacement-deflection were analyzed to help other researchers in the case when only one parameter would be measured during the 3PBT, and the calculation of residual strengths would be required. Additionally, formulas presented in the literature for the calculation of flexural tensile strength for FRC are usually dedicated to reinforcement with metallic fibers [42-45]. This study will fill the knowledge gap when it comes to the estimation of bending strength for polymer FRC with a nominal fiber content $\leq 1.0 \%$ and slenderness of up to 200 . Furthermore, an attempt was made to evaluate the tensile strengths in uniaxial tensile tests on samples significantly bigger than the one usually used in this kind of test $[45,46]$. It must be mentioned that the proprietary set-up was designed and used to execute this type of test. Concerning the classification of FRC according to Model Code 2010 [26], only a limited number of articles was found. Namely, in [46] Carlesso et al. classified the post-cracking strengths of FRC, but with a higher amount of polypropylene fibers from 5.0 to $10.0 \mathrm{~kg} / \mathrm{m}^{3}$. On the other hand, for similar $\mathrm{V}_{\mathrm{f}}$ the classification is done in [47]. Other research [48] also mentioned the toughness class, but for steel FRC. Moreover, since little work has been done using the DIC technique for polymer FRC subjected to 3PBT, the current study will help to enhance the knowledge in this area. The conclusions from the comparison of results from clip gauges and the DIC system will be beneficial for other researchers. It must be also mentioned that Glinicki in [13] performed similar studies with $2.0-3.9 \mathrm{~kg} / \mathrm{m}^{3}$ of macro synthetic fibers for industrial floors. However, they covered just the compressive strength test and four-point bending test according to ASTM C 1018-94 standard [49], so were different than presented in the current research. An extensive study on the effect of polypropylene fibers on the properties of concrete is also presented in [50]. Nevertheless, it did not deal with the issue of residual flexural tensile strengths and fracture energy. In [46], 3PBT was performed according to [29], though the amount of fibers was higher than the one proposed in the current study and was equal to $5.0-10.0 \mathrm{~kg} / \mathrm{m}^{3}$. Moreover, the work focused more on the fatigue behavior of polymer FRC. To sum up, according to the author's knowledge and prepared Table 1 , there is no research that simultaneously covers aspects of influence of synthetic fibers on workability; compressive, flexural, tensile strength and toughness, 
together with classification of post-cracking strengths according to Model Code 2010 [26] and complex study on empirical equations to explain the improvement in bending strength for no-metallic fibers.

Table 1. Research about the influence of synthetic FRC.

\begin{tabular}{|c|c|c|c|c|c|c|c|}
\hline Ref. & Workability & $\begin{array}{l}\text { Compressive } \\
\text { Strength }\end{array}$ & $\begin{array}{c}\text { Flexural Tensile } \\
\text { Strength acc. to } \\
\text { EN } 14651 \text { [28] }\end{array}$ & $\begin{array}{c}\text { Fracture } \\
\text { Energy }\end{array}$ & $\begin{array}{l}\text { Uniaxial } \\
\text { Tensile } \\
\text { Strength }\end{array}$ & $\begin{array}{c}\text { Model Code } \\
\text { Classification } \\
\text { [26] }\end{array}$ & $\begin{array}{c}\text { DIC } \\
\text { System }\end{array}$ \\
\hline [13] & $x$ & $x$ & $x^{1}$ & & & & \\
\hline [22] & & $x$ & $x^{1}$ & & $x$ & & \\
\hline [23] & $x$ & $x$ & $x^{1}$ & $x$ & & & \\
\hline [38] & & $x$ & & & & & $x$ \\
\hline [40] & & $x$ & $x$ & $x$ & & & $x$ \\
\hline [41] & & $x$ & $x$ & $x$ & & & $x$ \\
\hline$[46]$ & $x$ & $x$ & $x$ & & & $x$ & \\
\hline$[47]$ & $\mathrm{x}$ & $x$ & $x$ & & & $x$ & \\
\hline$[48]^{2}$ & $x$ & $x$ & $x$ & & & $x$ & \\
\hline$[50]$ & $x$ & $x$ & $x^{3}$ & & & & \\
\hline [51] & & $x$ & $x^{1}$ & & & & \\
\hline [52] & & $x$ & $x^{1}$ & & & & \\
\hline [53] & $x$ & $x$ & $x^{1}$ & $x$ & & & \\
\hline [54] & & & & & $x$ & & \\
\hline [55] & & $x$ & & & $x$ & & \\
\hline$[56]^{2}$ & & & & & $x$ & & \\
\hline This study & $x$ & $x$ & $x$ & $x$ & $x$ & $x$ & $x$ \\
\hline
\end{tabular}

${ }^{1}$ Acc. to different standard. ${ }^{2}$ Research on steel FRC. ${ }^{3}$ No information about the standard.

2. Materials and Methods

2.1. Materials

The tests were carried out with the use of three types of synthetic fibers, marked: PM, PD and FF. The scope of the research included the preparation of six concrete mixes: reference-without fibers (PC) and with the addition of: $3.0 \mathrm{~kg} / \mathrm{m}^{3}$ of PM fibers (PM_3); $2.0 \mathrm{~kg} / \mathrm{m}^{3}$ of PM fibers (PM_2); $3.0 \mathrm{~kg} / \mathrm{m}^{3}$ of PD fibers (PD_3); $2.0 \mathrm{~kg} / \mathrm{m}^{3}$ of PD fibers (PD_2); and $2.0 \mathrm{~kg} / \mathrm{m}^{3}$ of FF fibers (FF_2). The fibers added to the concrete mix are characterized in Table 2. All fibers had similar tensile strength $\left(\mathrm{f}_{\mathrm{t}}\right)$, chemical resistance, and their density was equal to $0.91 \mathrm{~g} / \mathrm{cm}^{3}$, melting point $160-170{ }^{\circ} \mathrm{C}$. On the other hand, they differed in dimensions and form, e.g., PM and FF fibers were longer and slender than PD fibers and were added to the mixture in the form of bundles, which disintegrate during mixing. In addition, Portland cement type I of the strength class 42.5 with high early strength (R)-CEM I 42.5R meeting the requirements of EN 197-1 [57] was used. Moreover, coarse pebble aggregate with a diameter of $2-8 \mathrm{~mm}$ was used, and as a fine-grained aggregate sand with a maximum diameter of $2 \mathrm{~mm}$. In order to ensure proper workability, a superplasticizer based on a modified acrylic polymer-MAPEI Dynamon SX 08 was added to the mixture. Pure water from the water supply network was used. The water-cement ratio (w/c) was equal to 0.50 . Each batch of mixes was prepared in a single excipient. All mixes were made on the same day, at a similar temperature and humidity. The composition of all concrete mixes is shown in Table 3. It is also worth noting that it was constant, and the only variable was nominal volume content $V_{f}$. 
Table 2. Characterization of fiber properties.

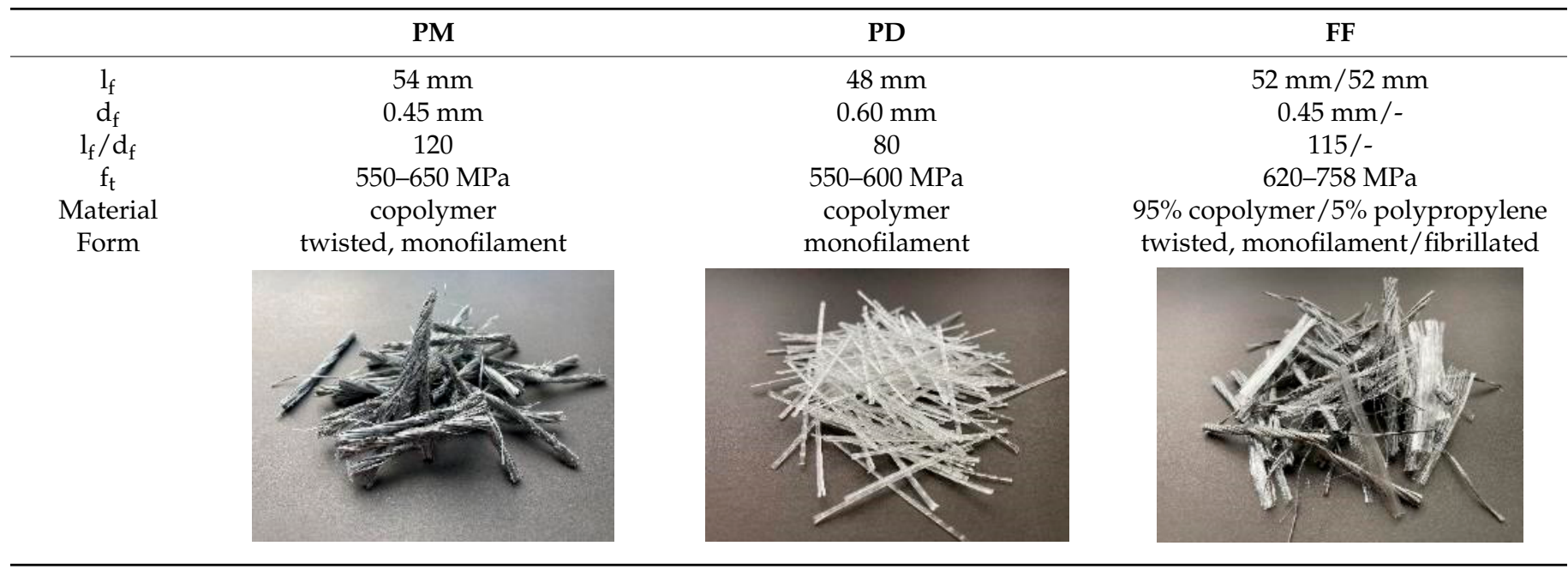

Table 3. Concrete mixture composition $\left[\mathrm{kg} / \mathrm{m}^{3}\right]$.

\begin{tabular}{|c|c|c|c|c|c|c|}
\hline Composition & PC & PM_3 & PM_2 & PD_3 & PD_2 & FF_2 \\
\hline CEM $42.5 R$ & \multicolumn{6}{|c|}{400} \\
\hline Pebble aggregate $2-8 \mathrm{~mm}$ & \multicolumn{6}{|c|}{1052} \\
\hline Sand 0-2 mm & \multicolumn{6}{|c|}{673} \\
\hline Water & \multicolumn{6}{|c|}{200} \\
\hline Superplasticizer & \multicolumn{6}{|c|}{1.43} \\
\hline $1 \mathrm{~W} / \mathrm{c}$ & \multicolumn{6}{|c|}{0.50} \\
\hline Fibers & 0.0 & 3.0 & 2.0 & 3.0 & 2.0 & 2.0 \\
\hline$V_{f}$ & $0.00 \%$ & $0.33 \%$ & $0.22 \%$ & $0.33 \%$ & $0.22 \%$ & $0.22 \%$ \\
\hline
\end{tabular}

All concrete mixes were prepared in the Zyklos planetary rotary mixer by Pemat (Pemat, Freisbach, Germany). Table 4 shows the mixing procedure used in the production of concrete. It is noteworthy that while dosing individual ingredients through a special hole in the mixer, the device was not stopped. After all the materials were mixed, the slump test was carried out according to the standard EN 12350-2 [58] in order to determine the consistency class of fresh concrete. In the beginning, the mold was filled with the first concrete layer and compacted manually by staking ( 25 times), then the above steps were repeated twice. When the cone was completely filled with the compacted mixture, it was evenly raised. Finally, the slump (h) was measured, which is equal to the difference between the height of the mold and the highest point of the cone. The consistency and slump of the tested concrete mixtures are shown in Figure 1, and the measurement results are presented in Table 5. Additionally, for concrete without fibers, a slump flow test was carried out in accordance with the EN 12350-8 standard [59], which is intended for self-compacting concretes, to check its fluidity. The test consisted of filling the cone with concrete mix and then raising it at a constant speed. When the concrete stopped flowing, two diameters perpendicular to each other were measured. Their length was 560 and $570 \mathrm{~mm}$, thus including PC in the SF1 slump flow class according to EN 206 [60]. In the case of mixtures with fibers, the slump flow tests were not possible to execute because their workabilities were too low. The tests show that the workability of the mixtures was significantly deteriorated due to the addition of synthetic fibers as was observed in different research i.e., [61]. Because of the incorporation of the additional surface to cover, the consistency class decreased by three for FF_2, two for PM_3, PD_3 and PD_2, and one for PM_2 compared to PC. A slight influence of $V_{f}$ was also visible, as in a mixture with $2.0 \mathrm{~kg} / \mathrm{m}^{3}$ of PM fibers, a greater drop of the cone was recorded than in the same mixture with $3.0 \mathrm{~kg} / \mathrm{m}^{3}$ of the same fibers. Furthermore, in the case of a mixture with hybrid fibers, the workability was the most severe. 
Table 4. Mixing procedure.

\begin{tabular}{cc}
\hline Procedure & Mixing Time \\
\hline $50 \%$ of pebble aggregate $+50 \%$ of sand & $1 \mathrm{~min}$ \\
$50 \%$ of CEM I $42.5 \mathrm{R}$ & $1 \mathrm{~min}$ \\
$100 \%$ of water $+100 \%$ of superplasticizer & $2 \mathrm{~min}$ \\
$100 \%$ of fibers & $1 \mathrm{~min}$ \\
$50 \%$ of pebble aggregate $+50 \%$ of sand $+50 \%$ CEM $42.5 \mathrm{R}$ & $2 \mathrm{~min}^{1}+{ }^{*}+1 \mathrm{~min}+{ }^{*}+1 \mathrm{~min}$ \\
\hline
\end{tabular}

${ }^{1}$ Only for mixes with fibers. ${ }^{*}$ Technical break to remove material on the walls and blades of the mixer.

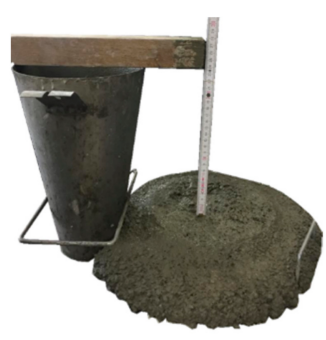

(a)

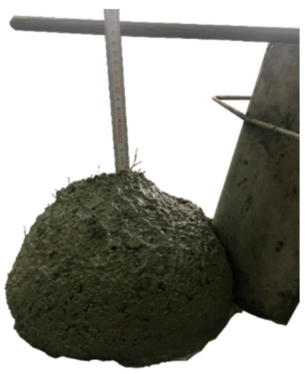

(c)

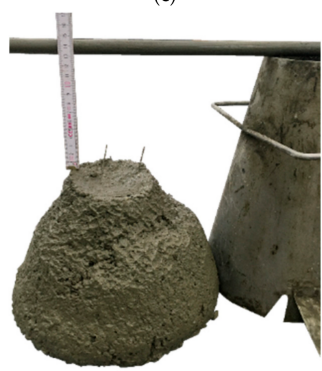

(e)

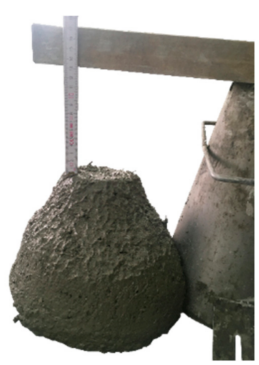

(b)

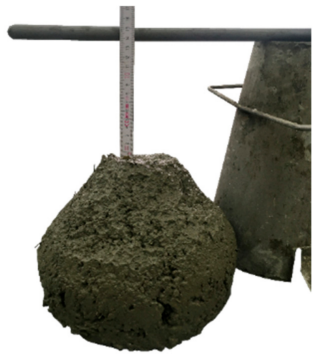

(d)

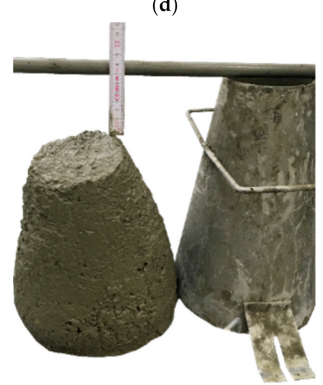

(f)

Figure 1. Slump test for concrete mixes: (a) PC; (b) PM_3; (c) PM_2; (d) PD_3; (e) PD_2; (f) FF_2.

Table 5. Slump classification according to EN 12350-2 [58].

\begin{tabular}{ccccccc}
\hline- & PC & PM_3 & PM_2 & PD_3 & PD_2 & FF_2 \\
\hline h [mm] & 230 & 130 & 160 & 140 & 140 & 65 \\
Consistency class & S5 & S3 & S4 & S3 & S3 & S2 \\
\hline
\end{tabular}

After testing the properties of fresh concrete mixtures, six cubes of dimensions $150 \times 150 \times 150 \mathrm{~mm}$ for compressive strength tests according to EN 206 [60] and six beams of dimensions $150 \times 150 \times 550 \mathrm{~mm}^{3}$ for flexural tensile strength tests in accordance with EN 14651 [28] for each type of concrete were concreted. Additionally, in order to test the tensile strength, one dog-bone specimen was concreted for each series with a height of $750 \mathrm{~mm}$, a middle cross-section of $100 \times 100 \mathrm{~mm}$, and a lower/upper cross-section of $100 \times 140 \mathrm{~mm}^{2}$. It must be noted that dog-bone specimens were specially reinforced by two layers of stirrups on both ends-on the 1/3 depth and 2/3 depth of the sample what is presented in Figure 2. This was done to force the crack occurrence in the middle 
of the sample. A total of 36 cubes, 18 beams and 6 dog-bone specimens were concreted (Table 6). All samples were stored under a foil and systematically watered to avoid drying and the appearance of shrinkage cracks. After 17 days, the cubes and beams were demolded and left in a room temperature at $20{ }^{\circ} \mathrm{C} \pm 2{ }^{\circ} \mathrm{C}$ and $\geq 95 \%$ humidity according to [62] until the test day (36 days for PC; 37 days for PM_3, PM_2, PD_3; 38 days for PD_2, FF_2.). Additionally, on day 18 , all beams in the middle of the span were cut $-5 \mathrm{~mm}$ wide and $25 \mathrm{~mm}$ deep along the entire beam width with a diamond saw in accordance with EN 14651 [28].

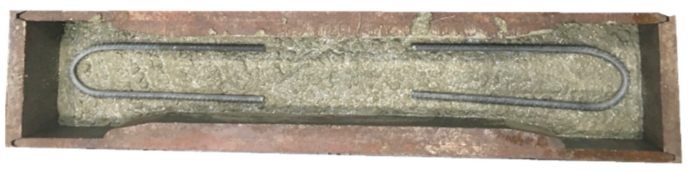

(a)

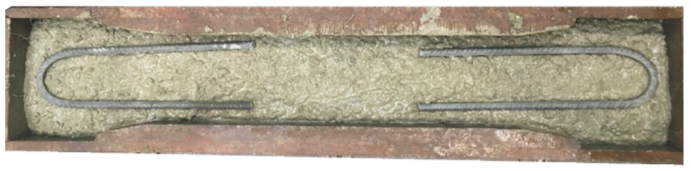

(b)

Figure 2. Casting of dog-bone specimens for uniaxial tensile test: (a) first layer of stirrups on the $1 / 3$ depth of the sample; (b) second layer of stirrups on the $2 / 3$ depth of the sample.

Table 6. Research program-number of studied samples for performed tests.

\begin{tabular}{ccccccc}
\hline Type of the Test & PC & PM_3 & PM_2 & PD_3 & PD_2 & FF_2 \\
\hline Compressive strength test & 6 & 6 & 6 & 6 & 6 & 6 \\
Flexural tensile test & 3 & 3 & 3 & 3 & 3 & 3 \\
Uniaxial tensile test & 1 & 1 & 1 & 1 & 1 & 1 \\
\hline
\end{tabular}

\subsection{Methods}

Regarding the compressive strength test, cubes with dimensions of $150 \times 150 \times 150 \mathrm{~mm}^{3}$ were tested in accordance with EN 206 [60]. The tests were performed on a Controls Model 50-C46CO2 machine (Controls, Liscate, Italy) where the stress was increased at a rate of $0.5 \mathrm{MPa} / \mathrm{sec}$ (Figure 3).

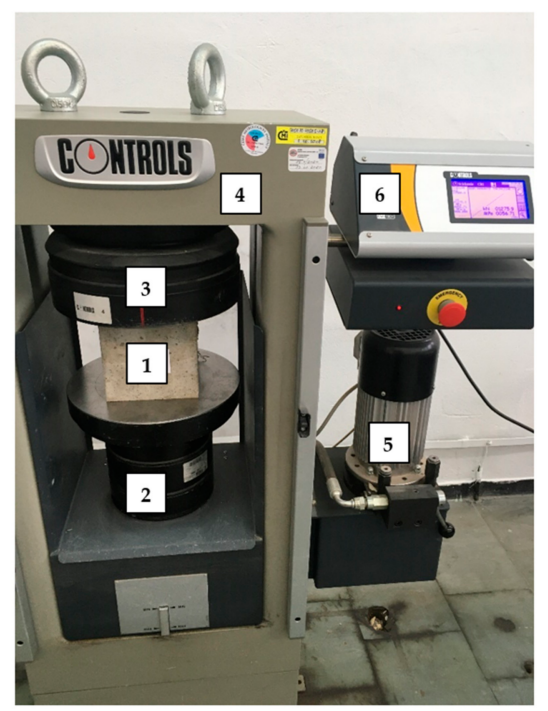

Figure 3. Set-up for compressive strength test: 1—sample; 2-fixed head; 3-movable head; 4 -frame; 5-motor; 6-digital display meter. 
The presented flexural tensile tests were performed in accordance with the EN 14651 standard [28], which is dedicated to 3PBT for metallic FRC in order to describe their flexural tensile strength. Figures 4 and 5 shows the test set-up with all sensors: linear variable differential transformer (LVDT) for measuring deflection $(\delta)$, clip gauges for measuring crack mouth opening displacement (CMOD) and crack tip opening displacement (CTOD), support frame and small steel angles enabling the installation of LVDT. As part of the research, free-supported beams with a cut in the middle and the following dimensions: $150 \times 150 \times 550 \mathrm{~mm}^{3}$ were tested. The span between the supports (1) was equal to $500 \mathrm{~mm}$. The samples were loaded with a force (F) in the middle of the span with a constant increment of $\delta$ equal to $0.2 \mathrm{~mm} / \mathrm{min}$ until reaching $\delta=5 \mathrm{~mm}$, i.e., until the end of the test. During the test, three curves were recorded, F-CMOD, F- $\delta$ and F-CTOD, though according to EN 14651 [28], the first one is used for the strength characteristics of FRC. Nevertheless, there is a formula (Equation (1)) to calculate the CMOD value using $\delta$.

$$
\delta=0.85 \mathrm{CMOD}+0.04
$$

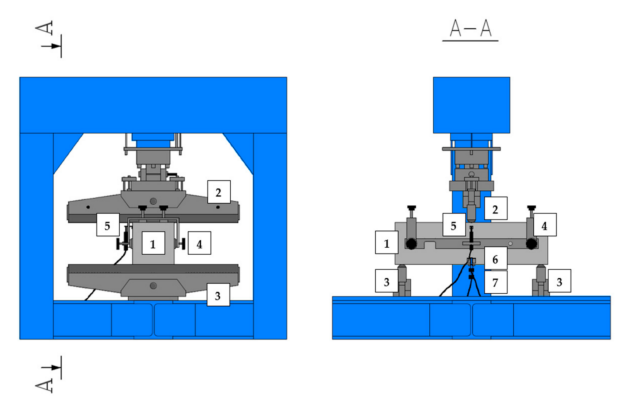

Figure 4. Set-up for three-point bending test: 1-sample; 2-loading roller; 3 -supporting roller; 4 -rigid frame to install LVDT; 5 -LVDT to measure $\delta$; 6 - clip gauge to measure CTOD; 7—clip gauge to measure CMOD.

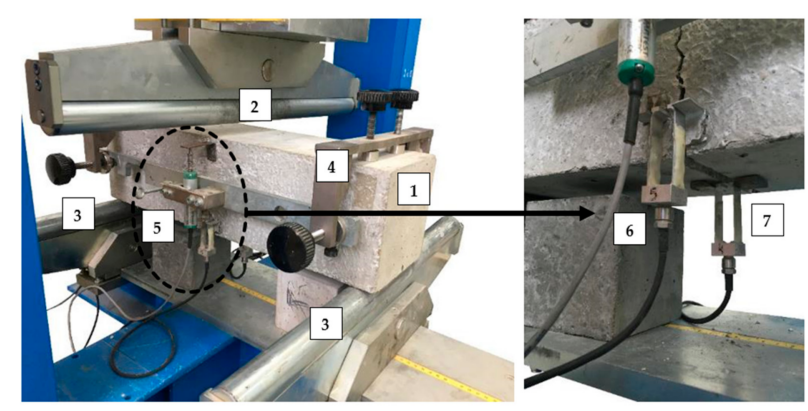

Figure 5. Picture of the sample during the three-point bending test: 1 -sample; 2-loading roller; 3-supporting roller; 4-rigid frame to install LVDT; 5-LVDT to measure $\delta$; 6 - clip gauge to measure CTOD; 7-clip gauge to measure CMOD.

Thanks to the obtained graphs F-CMOD and F- $\delta$, it was possible to determine the flexural tensile strength in the range of limit of proportionality $\mathrm{f}_{\mathrm{ct}, \mathrm{L}}^{\mathrm{f}}$, (Equation (2)) and residual flexural tensile strengths: $f_{R, 1}, f_{R, 2}, f_{R, 3}$ and $f_{R, 4}$ (Equation (3)), using the formulas included in the EN 14651 standard [28]. It must be mentioned that for F-CMOD plot obtained during testing of $\mathrm{FRC}, \mathrm{CMOD}_{1}=0.5 \mathrm{~mm}, \mathrm{CMOD}_{2}=1.5 \mathrm{~mm}, \mathrm{CMOD}_{3}=2.5 \mathrm{~mm}$ and $\mathrm{CMOD}_{4}=3.5 \mathrm{~mm}$.

$$
\begin{gathered}
\mathrm{f}_{\mathrm{ct}, \mathrm{L}}^{\mathrm{f}}=\frac{3 \mathrm{~F}_{\mathrm{L}} \mathrm{l}}{2 \mathrm{bh}_{\mathrm{sp}}^{2}} \\
\mathrm{f}_{\mathrm{R}, \mathrm{j}}=\frac{3 \mathrm{~F}_{\mathrm{j}} \mathrm{l}}{2 \mathrm{bh}_{\mathrm{sp}}^{2}}
\end{gathered}
$$

where: 
$\mathrm{f}_{\mathrm{ct}, \mathrm{L}}^{\mathrm{f}}$ limit of proportionality $\left[\mathrm{N} / \mathrm{mm}^{2}\right]$;

$\mathrm{f}_{\mathrm{R}, \mathrm{j}}$-residual flexural tensile strength corresponding to $\mathrm{CMOD}=\mathrm{CMOD}_{\mathrm{j}}$ or $\delta=\delta_{\mathrm{j}}(\mathrm{j}=1,2$, $3,4)\left[\mathrm{N} / \mathrm{mm}^{2}\right]$;

$\mathrm{F}_{\mathrm{L}}$ - load corresponding to the limit of proportionality $[\mathrm{N}]$;

$\mathrm{F}_{\mathrm{j}}$-load corresponding to $\mathrm{CMOD}=\mathrm{CMOD}_{\mathrm{j}}$ or $\delta=\delta_{\mathrm{j}}(\mathrm{j}=1,2,3,4)[\mathrm{N}]$;

1 -span length [mm]-500 $\mathrm{mm}$;

$\mathrm{b}$ - width of the specimen [mm]-150 $\mathrm{mm}$;

$\mathrm{h}_{\mathrm{sp}}$-distance between the tip of the notch and the top of the specimen [mm] $-150 \mathrm{~mm}-$ $25 \mathrm{~mm}=125 \mathrm{~mm}$.

The uniaxial tensile test was performed on larger samples than those usually used in the tests $[56,63,64]$. In order to execute it, a special set-up was constructed visible in Figures 6 and 7. Red bars were mounted to maintain the sample in the vertical position during the tests and black ones to hold two parts of the specimens after cracking. The tensile force was applied manually from the top of the set-up. Additionally, in the middle of the specimens, from both sides, two LVDTs were installed to measure the extension of the sample assuming that the crack will occur somewhere in the middle, within measured distance of $100 \mathrm{~mm}$. The aim was to obtain the stress-crack opening $(\sigma-w)$ diagram.
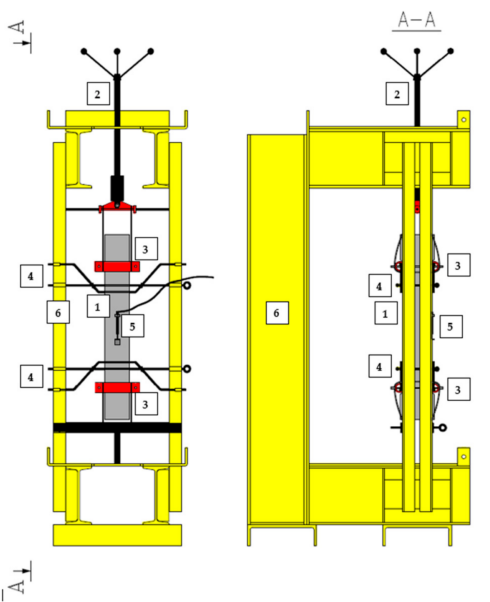

Figure 6. Set-up for uniaxial tensile test: 1-sample; 2-manual load application; 3-grip; 4-bar assembling to prevent falling down of the sample after failure; 5-LVDT to measure w; 6-rigid frame.

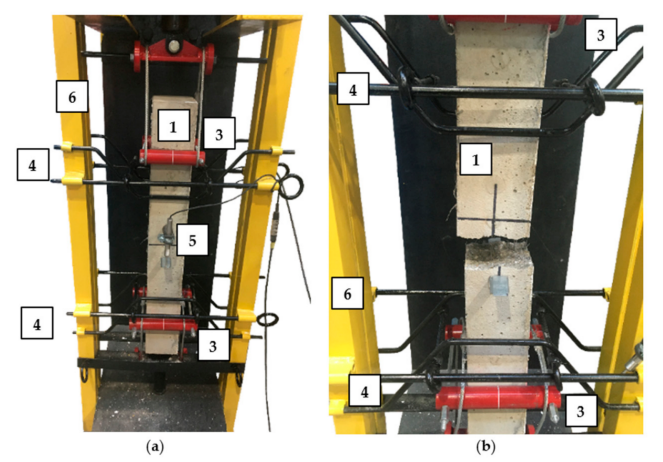

Figure 7. Picture of the sample: (a) before the uniaxial tensile test; (b) after the uniaxial tensile test: 1—sample; 3-grip; 4-bar assembling to prevent falling down of the sample after failure; 5-LVDT to measure $\mathrm{w} ; 6$-rigid frame.

The Digital Image Correlation technique is based on the idea of comparing the random speckle pattern, which was sprayed on the studied surface, of a reference image with the speckles in deformed images during the test. Thanks to this, it is possible to track the deformations and create the local strain map which allows to characterize both the fracture process zone and the crack. The aim to use the DIC technique was to compare the values of 
CMOD and CTOD measured in the DIC system with the ones from the clip gauges, and to visualize the crack propagation and to analyze the strain. The set-up of the DIC system is presented in Figure 8. Moreover, the facets had size of $15 \times 15$ pixels and the images were taken with the frequency $0.5 \mathrm{~Hz}$ (1 image every $2 \mathrm{~s}$ ), and kept in the computer memory for later analysis.

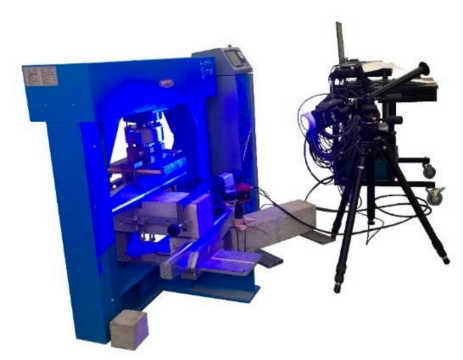

(a)

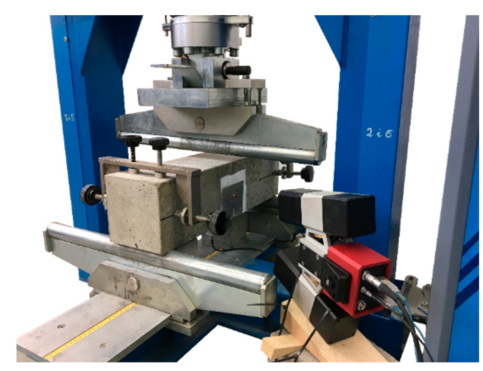

(b)

Figure 8. Set-up for monitoring the samples using the DIC system: (a) computer for storage the data with the lamp to lightened the studied surface; (b) camera.

\section{Results and Discussion}

\subsection{Compressive Strength}

For each concrete mix, six cubes with dimensions of $150 \times 150 \times 150 \mathrm{~mm}^{3}$ were tested for compressive strength $\left(f_{c}\right)$ in accordance with EN 206 [60]. The tests were performed on a Controls Model 50-C46CO2 machine (Controls, Liscate, Italy) where the stress was increased at a rate of $0.5 \mathrm{MPa} / \mathrm{sec}$. The mean $\mathrm{f}_{\mathrm{cm}}$, standard deviation $\mathrm{s}_{\mathrm{fc}}$, and the coefficient of variation $\mathrm{V}_{\mathrm{fc}}$ of the compressive strength for PC, PM_3, PM_2, PD_3, PD_2, and FF_2 are summarized in Table 7. It should be noted that samples no. 5 for PC and PD_2 and sample no. 6 for PM_3 were rejected during the analysis, as they significantly differed from the other results. This could be due to inaccurate mixing of the concrete components at the bottom of the mixer, as the samples were concreted as one of the last in the series.

Table 7. Compressive strength for all samples for individual concrete mixes.

\begin{tabular}{|c|c|c|c|c|c|c|c|c|c|c|}
\hline No. & Property & \multicolumn{3}{|c|}{ PC } & \multicolumn{3}{|c|}{ PM_3 } & \multicolumn{3}{|c|}{ PM_2 } \\
\hline 1 & \multirow{6}{*}{$\sum_{\Perp}^{\tilde{U}}$} & 57.49 & $\mathrm{f}_{\mathrm{cm}}[\mathrm{MPa}]$ & 58.05 & 56.61 & $\mathrm{f}_{\mathrm{cm}}[\mathrm{MPa}]$ & 58.06 & 61.50 & $\mathrm{f}_{\mathrm{cm}}[\mathrm{MPa}]$ & 60.64 \\
\hline 2 & & 58.40 & $\mathrm{~s}_{\mathrm{fc}}[\mathrm{MPa}]$ & 1.33 & 58.65 & $\mathrm{~s}_{\mathrm{fc}}[\mathrm{MPa}]$ & 1.10 & 64.57 & $\mathrm{~s}_{\mathrm{fc}}[\mathrm{MPa}]$ & 2.20 \\
\hline 3 & & 59.89 & $\mathrm{~V}_{\mathrm{fc}}[\%]$ & 2.29 & 57.23 & $\mathrm{~V}_{\mathrm{fc}}[\%]$ & 1.89 & 58.91 & $\mathrm{~V}_{\mathrm{fc}}[\%]$ & 3.64 \\
\hline 4 & & 58.21 & $\mathrm{f}_{\mathrm{c} ; 0.05}[\mathrm{MPa}]$ & 57.26 & 59.27 & $\mathrm{f}_{\mathrm{c} ; 0.05}[\mathrm{MPa}]$ & 57.34 & 60.03 & $\mathrm{f}_{\mathrm{c} ; 0.05}[\mathrm{MPa}]$ & 59.14 \\
\hline 5 & & 63.92 & & & 58.52 & & & 58.48 & & \\
\hline 6 & & 56.26 & & & 32.85 & & & 60.34 & & \\
\hline No. & Property & \multicolumn{3}{|c|}{ PD_3 } & \multicolumn{3}{|c|}{ PD_2 } & \multicolumn{3}{|c|}{ FF_2 } \\
\hline 1 & & 56.71 & $\mathrm{f}_{\mathrm{cm}}[\mathrm{MPa}]$ & 59.44 & 59.79 & $\mathrm{f}_{\mathrm{cm}}[\mathrm{MPa}]$ & 61.31 & 60.73 & $\mathrm{f}_{\mathrm{cm}}[\mathrm{MPa}]$ & 60.87 \\
\hline 2 & $\sigma$ & 59.59 & $\mathrm{~s}_{\mathrm{fc}}[\mathrm{MPa}]$ & 2.77 & 64.10 & $\mathrm{~s}_{\mathrm{fc}}[\mathrm{MPa}]$ & 1.81 & 60.71 & $\mathrm{~s}_{\mathrm{fc}}[\mathrm{MPa}]$ & 0.72 \\
\hline 3 & $\Leftrightarrow$ & 60.45 & $\mathrm{~V}_{\mathrm{fc}}[\%]$ & 4.66 & 62.02 & $\mathrm{~V}_{\mathrm{fc}}[\%]$ & $2.95 \%$ & 61.93 & $\mathrm{~V}_{\mathrm{fc}}[\%]$ & 1.19 \\
\hline 4 & $\Sigma$ & 61.80 & $\mathrm{f}_{\mathrm{c} ; 0.05}[\mathrm{MPa}]$ & 57.55 & 60.84 & $\mathrm{f}_{\mathrm{c} ; 0.05}[\mathrm{MPa}]$ & 60.23 & 61.43 & $\mathrm{f}_{\mathrm{c} ; 0.05}[\mathrm{MPa}]$ & 60.38 \\
\hline 5 & 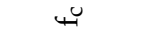 & 55.57 & & & 55.54 & & & 60.59 & & \\
\hline 6 & & 62.50 & & & 59.81 & & & 59.84 & & \\
\hline
\end{tabular}

The addition of fibers to the concrete mix increased the $\mathrm{f}_{\mathrm{cm}}$ of the PM_2; PD_3; PD_2, and FF_2 by respectively $4.5 ; 2.4 ; 5.6$, and $4.9 \%$ and did not affect the $\mathrm{f}_{\mathrm{cm}}$ of the PM_3 series when comparing with the PC (Figure 9). Moreover, it can be seen that the reduction of $V_{\mathrm{f}}$ from $3 \mathrm{~kg} / \mathrm{m}^{3}$ to $2 \mathrm{~kg} / \mathrm{m}^{3}$ had a positive effect on $\mathrm{f}_{\mathrm{cm}}$. On the other hand, the means of individual FRC mixes were from 58.05 to $61.31 \mathrm{MPa}$, standard deviations from 0.72 to $2.77 \mathrm{MPa}$, and the coefficients of variation from 1.19 to $4.66 \%$, which showed that the variation between the series was not very large. The conclusion can be made that the type and the amount of fibers did not significantly affect the $\mathrm{f}_{\mathrm{cm}}$, which is in agreement 
with many other studies, e.g., [65-67]. It is also worth noting that the clear deterioration of the workability of the concrete did not have a negative effect on the $\mathrm{f}_{\mathrm{c}}$. Additionally, the $5 \%$ quantile of the concrete compressive strength $\left(\mathrm{f}_{\mathrm{c} ; 0.05}\right)$ was calculated, which means the probability of occurring the value of $f_{c}$ less than 0.05 . For the distribution of $t$-non-centrifugal with a one-sided rejection region, the quantile can be determined from Equation (4). The results of the $\mathrm{f}_{\mathrm{c} ; 0.05}$ calculations are presented in Table 7 .

where:

$$
\mathrm{f}_{\mathrm{c} ; 0.05}=\mathrm{f}_{\mathrm{cm}}-\mathrm{t}_{\mathrm{n}-1, \alpha} \frac{\mathrm{s}_{\mathrm{fc}}}{\sqrt{\mathrm{n}}}
$$

$\mathrm{n}$-number of samples ( $\mathrm{n}=6$ or 5$)$ [-];

$\mathrm{s}_{\mathrm{fc}}$-standard deviation of compressive strength [MPa];

$t_{n-1, \alpha}$-with a confidence level of $\alpha=0.05$, for six samples $(n-1=5)-t_{5 ; 0.05}=1.67$, for five samples $(\mathrm{n}-1=4)-\mathrm{t}_{4 ; 0.05}=1.46[-]$.

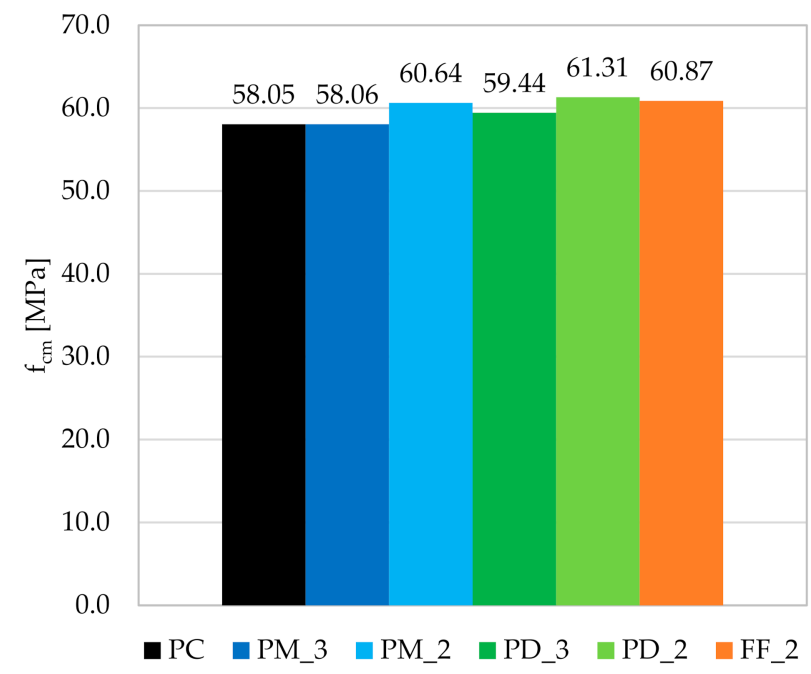

Figure 9. Graph of the mean compressive strength $\mathrm{f}_{\mathrm{cm}}$ for individual concrete mixes.

\subsection{Flexural Tensile Strength}

Within a three-point bending tests according to EN 14651 [28], three beams were examined for each of the concrete mixes. As a result of the measurement of F and CMOD, the F-CMOD graphs presented in Figure 10 were made for each mixture. All plots of the averaged F-CMOD curves for each series are visible in Figure 11. In the beginning, in accordance with the test methodology, the loads corresponding to the maximum load for $\mathrm{CMOD} \leq 0.05 \mathrm{~mm}\left(\mathrm{~F}_{\mathrm{L}}\right)$ and to $\mathrm{CMOD}=0.5\left(\mathrm{~F}_{1}\right) ; 1.5\left(\mathrm{~F}_{2}\right) ; 2.5\left(\mathrm{~F}_{3}\right)$, and $3.5 \mathrm{~mm}\left(\mathrm{~F}_{4}\right)$ were determined for the tested concrete mixes (Table 8). Subsequently, the flexural tensile strength in the range of limit of proportionality $\left(\mathrm{f}_{\mathrm{ct}, \mathrm{L}}^{\mathrm{f}}\right)$ and residual strengths: $\mathrm{f}_{\mathrm{R}, 1} ; \mathrm{f}_{\mathrm{R}, 2} ; \mathrm{f}_{\mathrm{R}, 3}$; $\mathrm{f}_{\mathrm{R}, 4}$ were calculated and are shown in Figure 12. 


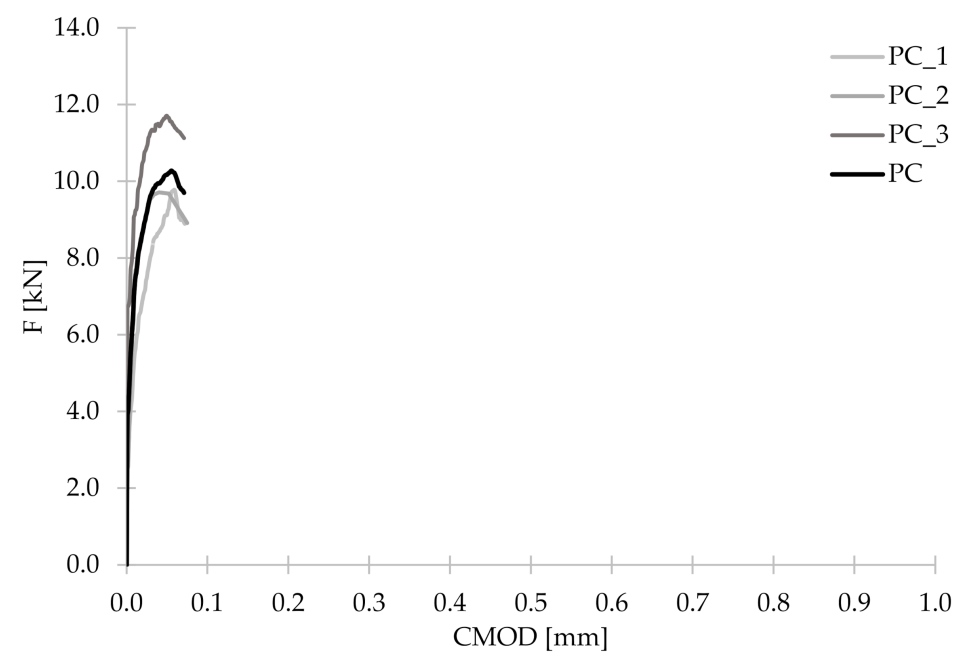

(a)

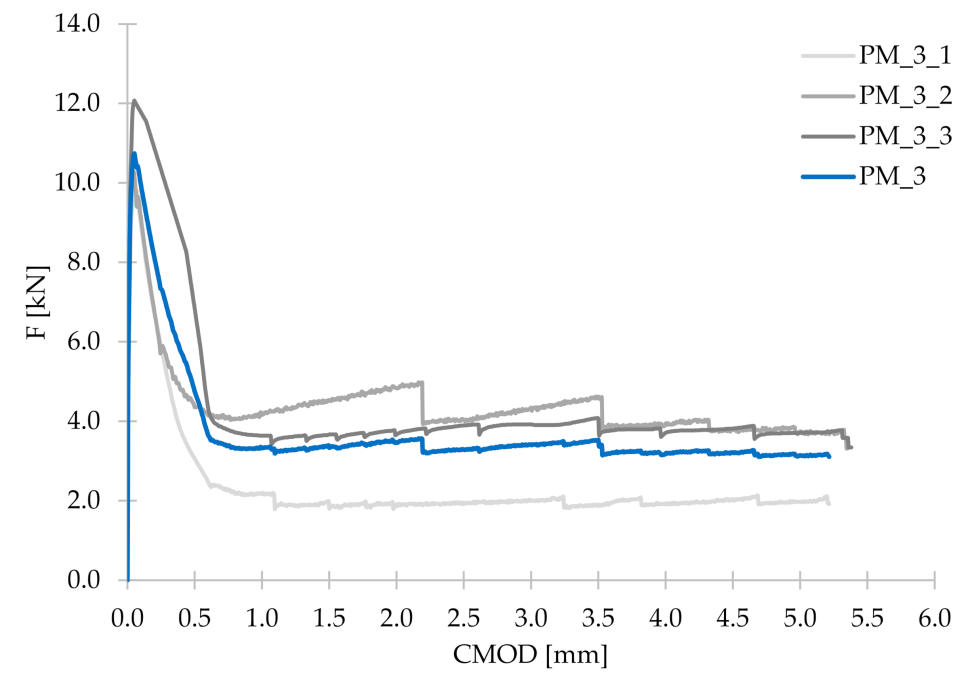

(b)

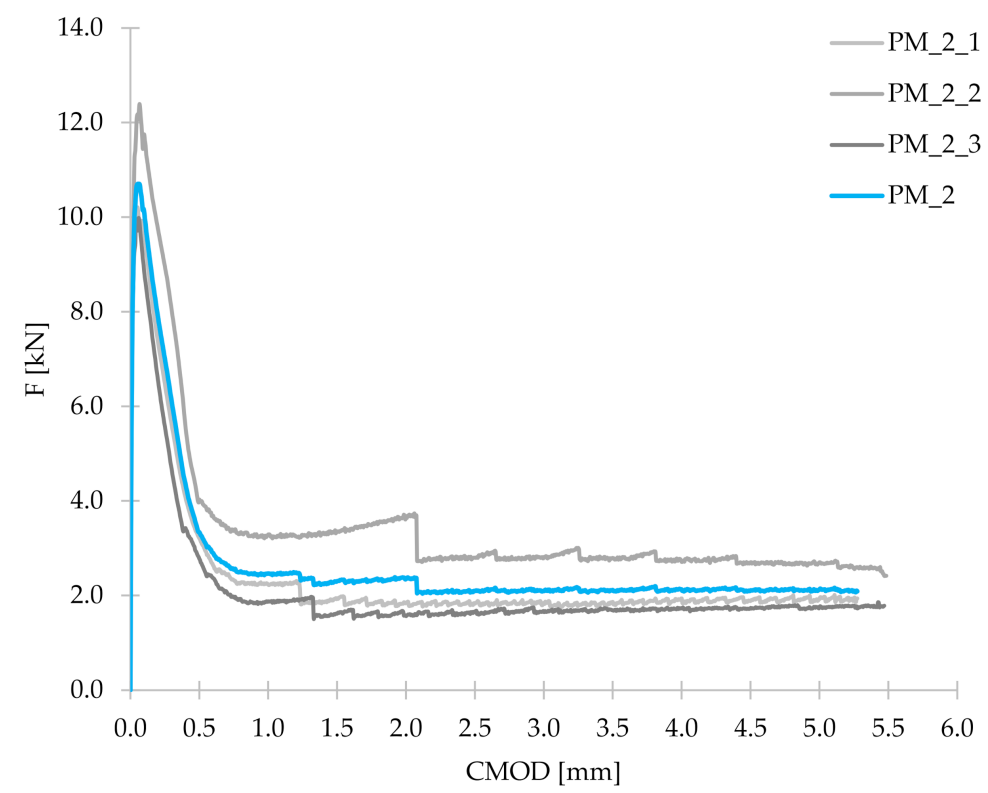

(c)

Figure 10. Cont. 


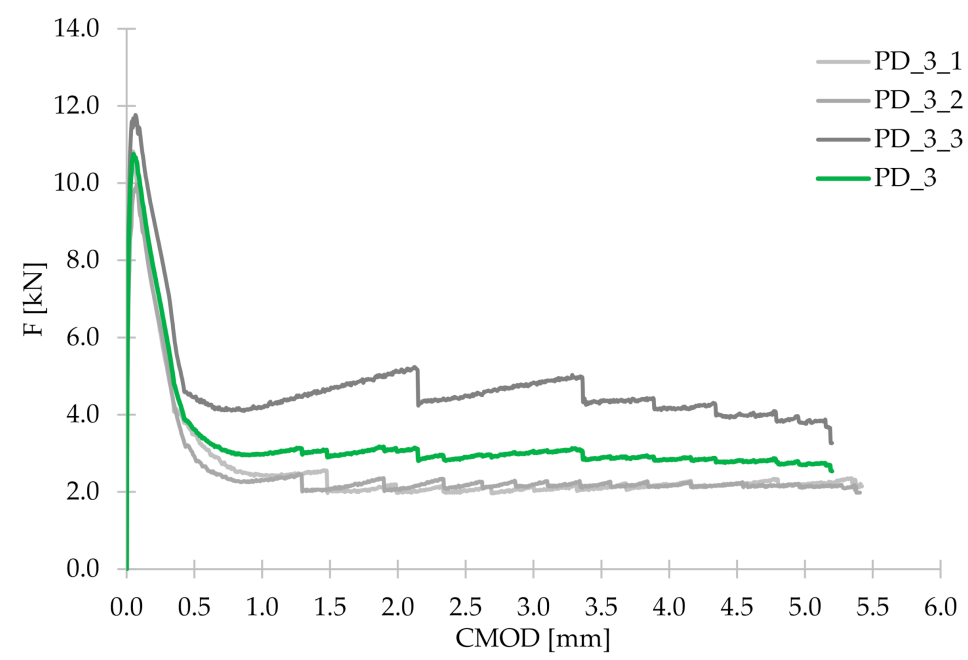

(d)

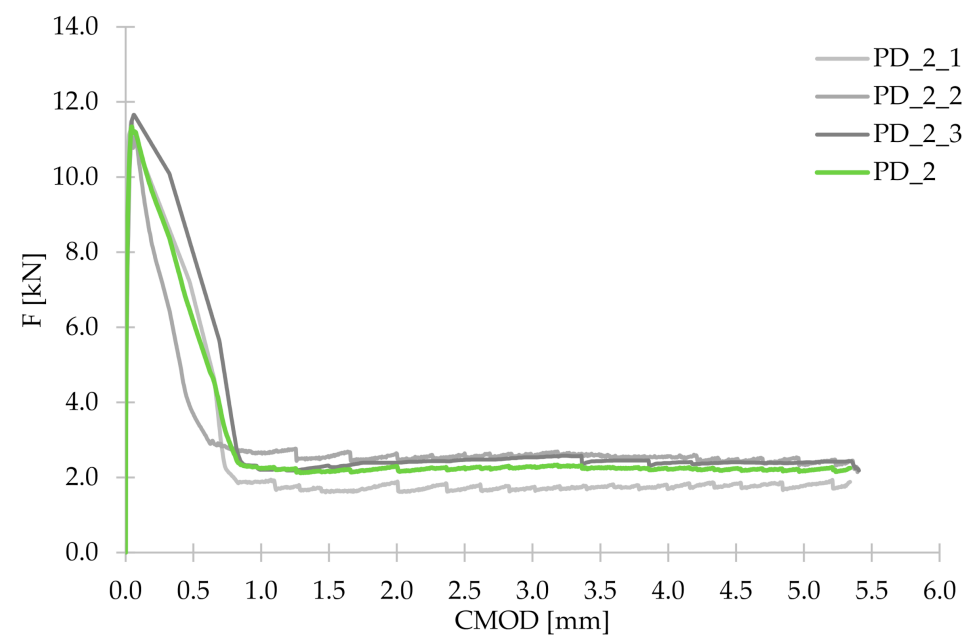

(e)

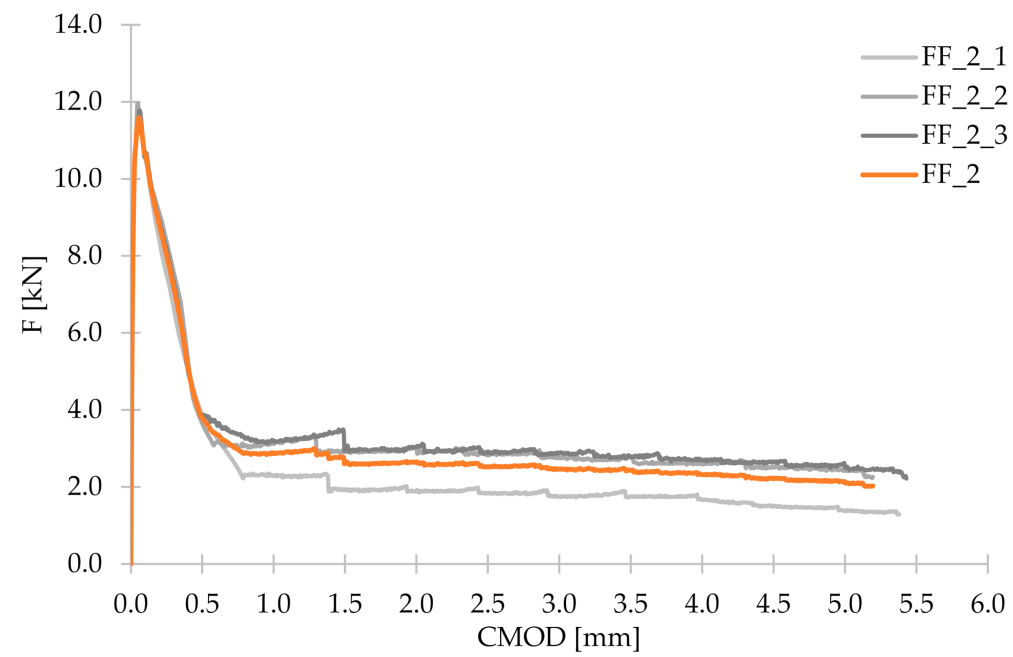

(f)

Figure 10. Graphs of mean F-CMOD curves for (a) PC; (b) PM_3; (c) PM_2; (d) PD_3; (e) PD_2; (f) FF_2 with graphs of the individual samples within the series. 


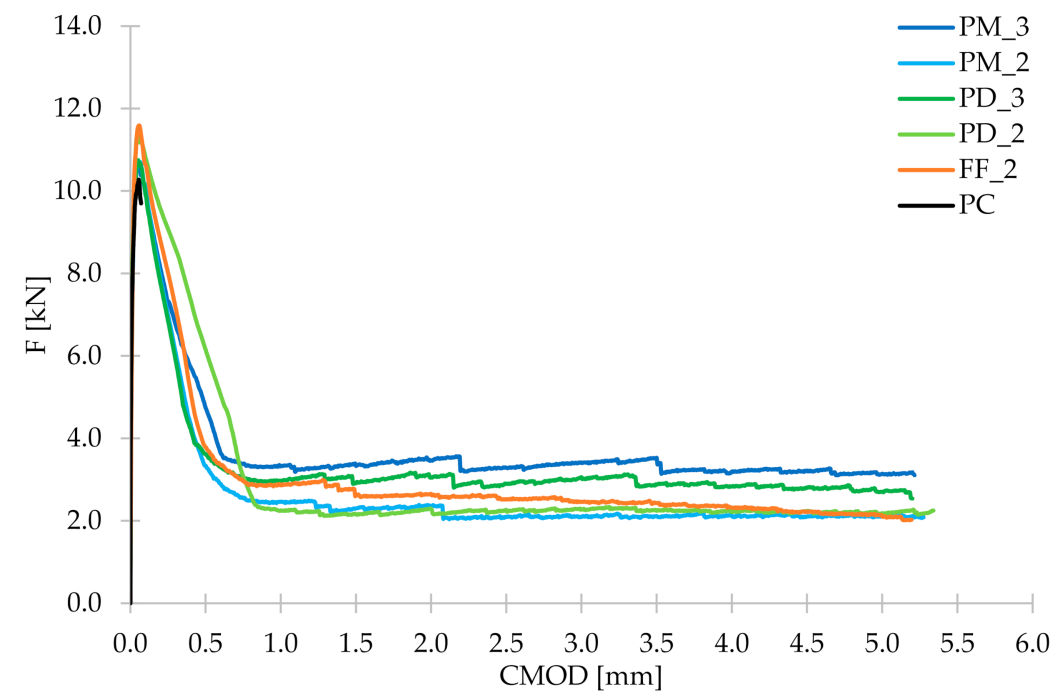

Figure 11. Graphs of mean F-CMOD curves for all concrete mixes.

Table 8. Force values corresponding to the limit of proportionality $\left(\mathrm{F}_{\mathrm{L}}\right)$ and $\mathrm{CMOD}=0.5\left(\mathrm{~F}_{1}\right) ; 1.5\left(\mathrm{~F}_{2}\right)$; $2.5\left(\mathrm{~F}_{3}\right)$ and $3.5 \mathrm{~mm}\left(\mathrm{~F}_{4}\right)$ for tested concrete mixtures.

\begin{tabular}{ccccccc}
\hline Ref. & PC & PM_3 & PM_2 & PD_3 & PD_2 & FF_2 \\
\hline $\mathrm{F}_{\mathrm{L}}[\mathrm{kN}]$ & 10.17 & 10.74 & 10.70 & 10.75 & 11.34 & 11.55 \\
$\mathrm{~F}_{1}[\mathrm{kN}]$ & - & 4.74 & 3.34 & 3.62 & 6.15 & 3.78 \\
$\mathrm{~F}_{2}[\mathrm{kN}]$ & - & 3.33 & 2.30 & 2.91 & 2.15 & 2.61 \\
$\mathrm{~F}_{3}[\mathrm{kN}]$ & - & 3.29 & 2.09 & 2.90 & 2.27 & 2.53 \\
$\mathrm{~F}_{4}[\mathrm{kN}]$ & - & 3.53 & 2.12 & 2.88 & 2.25 & 2.43 \\
\hline
\end{tabular}

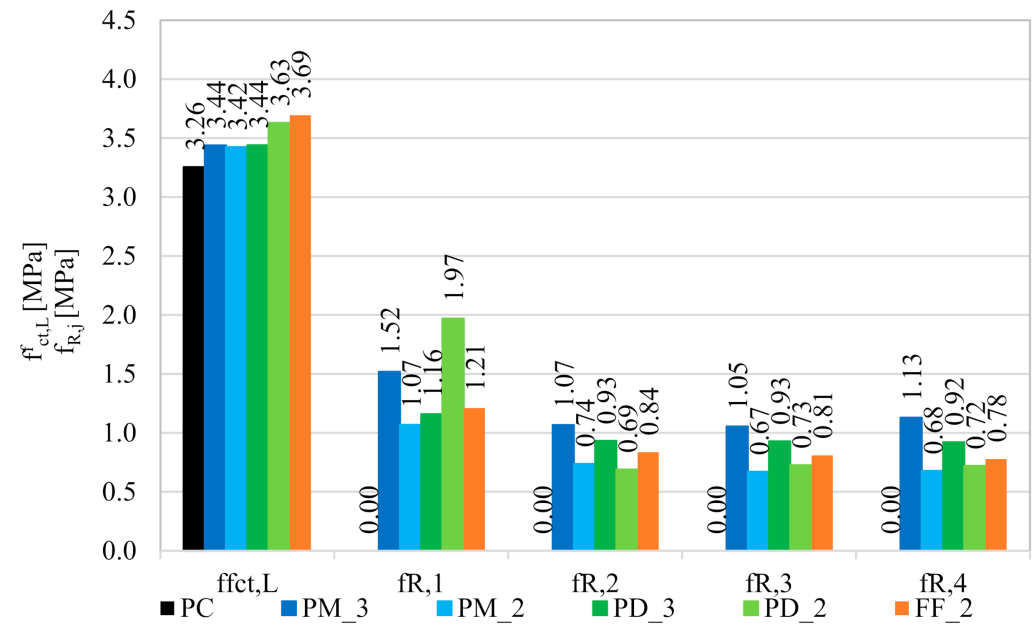

Figure 12. Comparison of the mean values of the flexural tensile strength in the range of limit of proportionality $\left(\mathrm{f}_{\mathrm{ct}, \mathrm{L}}^{\mathrm{f}}\right)$ and residual flexural tensile strengths $\left(\mathrm{f}_{\mathrm{R}, \mathrm{j}}\right)$ for the tested concrete mixtures.

As a result of the addition of synthetic fibers to concrete, $\mathrm{f}_{\mathrm{ct}, \mathrm{L}}^{\mathrm{f}}$ increased approximately by 5.5\% for PM_3, PM_2, and PD_3 by 11.5\% for PD_2 and by 13.5\% for FF_2. In conclusion, the smallest improvement was noted in the case of a mixture with one type of fibers, and higher $1_{\mathrm{f}}$. Mixes with slightly shorter fibers $\left(\mathrm{l}_{\mathrm{f}}=48 \mathrm{~mm}\right)$ performed better, in particular where fewer fibers $\left(2 \mathrm{~kg} / \mathrm{m}^{3}\right)$ have been used. However, the best results were obtained for a hybrid blend with $V_{f}=2 \mathrm{~kg} / \mathrm{m}^{3}$. This may be because of the fact that the combination of two types of fibers more effectively bridged the cracks that appear in the initial stage of cracking, and the lower fiber content allowed for more even distribution of all fibers in the concrete. Furthermore, 
when comparing the results with the ones obtained in the other literature positions, it occurred that the level of enhancement in the flexural tensile strength $\left(\mathrm{f}_{\mathrm{fl}}\right)$ is in agreement with many of them. For example in [68], where $\mathrm{V}_{\mathrm{f}}$ was equal to $0.33 \%$, fibers were $60 \mathrm{~mm}$ long and with a diameter of $1.0 \mathrm{~mm}, \mathrm{f}_{\mathrm{fl}}$ increased by $6.24 \%$. Additionally, Meza et al. reported in [69] that the addition of $2.7 \mathrm{~kg} / \mathrm{m}^{3}$ of copolymer $\left(\mathrm{l}_{\mathrm{f}} / \mathrm{d}_{\mathrm{f}}=38 \mathrm{~mm} / 2.0 \times 0.5 \mathrm{~mm}\right)$ fibers resulted in $6.44 \%$ increase of $\mathrm{f}_{\mathrm{fl}}$. Finally, Rucka et al. in [40] tested exactly the same type of fibers PM with the dosage equaled to $2 \mathrm{~kg} / \mathrm{m}^{3}$ what resulted in a $6.83 \% \mathrm{f}_{\mathrm{fl}}$ increase. There also exist studies in which the improvement in strength was smaller, even though fibers with similar length and content were used, namely $\mathrm{f}_{\mathrm{fl}}$, which increased from 2.96 to $4.41 \%$, depending on the $V_{f}$ in [70]. In the other case, comparable enhancement was obtained for almost twice higher amount of fibers, like in [71] where after the addition of $0.50 \%$ of polypropylene fibers $\left(\mathrm{l}_{\mathrm{f}} / \mathrm{d}_{\mathrm{f}}=38 \mathrm{~mm} / 0.91 \mathrm{~mm}\right) \mathrm{f}_{\mathrm{fl}}$ increased from 3.25 to $3.70 \mathrm{MPa}$, so by $13.8 \%$. One should also take into account the fact that in many studies the decrease of $\mathrm{f}_{\mathrm{fl}}$ was noted despite the addition of fibers, like in [72-74].

In the case of plain concrete, there was a sudden, brittle failure after cracking and it was impossible to determine its residual strengths. Figure 13 presents the sample PC_1 immediately after the bending test, which caused it to split in two. On the other hand, FRC beams, after a decrease in the transferred force, were still able to resist significant load with increasing CMOD. Therefore, in the non-elastic range, an improvement in ductility is seen after the addition of fibers. From the comparison of the residual strengths for different FRC mixes it can be concluded that usually $f_{R, j}$ reached higher values when the fiber content was higher, so $\mathrm{V}_{\mathrm{f}}=0.33 \%$ (Figures 11 and 12). Moreover, after cracking, the PM_3 beam behaved best, wherein higher $V_{\mathrm{f}}$ and longer fibers with $\mathrm{l}_{\mathrm{f}}=54 \mathrm{~mm}$ were added, so those that will more efficiently bridge the macrocracks appearing in the second phase of cracking. It is also noteworthy that among the mixtures with $2 \mathrm{~kg} / \mathrm{m}^{3}$ the highest $\mathrm{f}_{\mathrm{R}, 2} ; \mathrm{f}_{\mathrm{R}, 3}$; and $\mathrm{f}_{\mathrm{R}, 4}$ are achieved for FF_2 series, which may again indicate the positive effect of combining two types of fibers. The graphs of F-CMOD for FRC (Figure 10) also show some vertical jumps, which were the result of fibers' failure in the crack cross-section. Failure mechanisms of concrete with fibers are presented and described in Figure 14. Namely, it can be said that in an uncracked concrete the fibers are inactive, however when micro-and macro-cracks occur (6 and 3, respectively), fibers start to bridge them and transfer tensile stresses [75]. Additionally, fibers can prevent further propagation of the crack's tip (5). Later on, it can happen that fibers will debond from the matrix (4); pull-out (2), or rupture (1), and it will lead to absorption and dissipation of some energy, as a result, stabilization of crack growth in the concrete [75]. It must be noted that in the current study, the rupture of fibers was observed. Often, after breaking the fiber, there was a slight strengthening of the concrete, as the force that it was able to transfer increased with increasing CMOD. It was visible during the analysis of $f_{R, j}$ for: PM_3, where $f_{R, 4}>f_{R, 3} ; P M \_2$, where $f_{R, 4}>f_{R, 3}$; PD_2, where $f_{R, 3}>f_{R, 2}$ and in Figures 11 and 12. It should also be mentioned that the results for individual samples within the series indicated a significant dispersion of the F-CMOD curves, which was a result of a small fracture area, and thus a large statistical variability of the amount of fibers crossing this surface [76]. Therefore, when testing according to EN 14651 [28], a larger number of samples should be studied. Nevertheless, thanks to this method, which is intended for testing concretes with metallic fibers, a smaller scatter of results is obtained for samples with synthetic fibers than for steel ones $[10,76,77]$. This can be a result of a more homogeneous distribution of non-metallic fibers than metallic fibers in the concrete mix. It is also worth paying attention to the fact that after the end of the test the FRC beams did not split in half, but retained their integrity. Moreover, all the beams were damaged by a quasi-vertical crack beginning in the sample notch. 


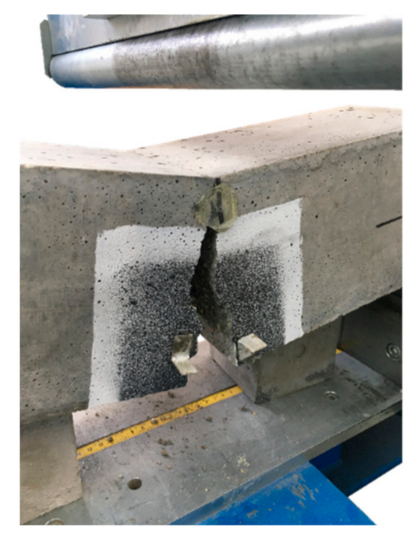

Figure 13. PC_1 beam without fibers after the three-point bending test.

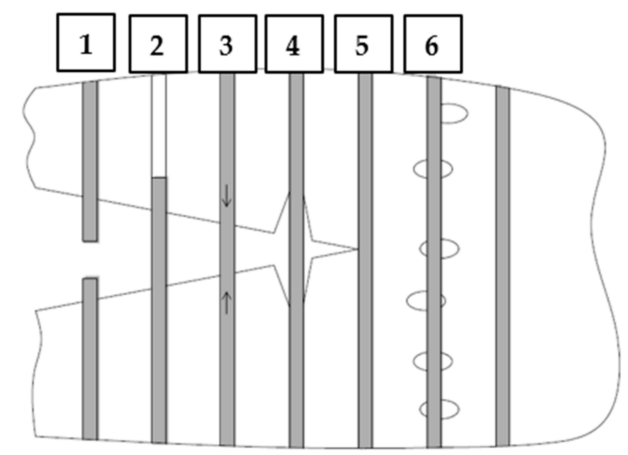

Figure 14. Failure mechanisms of FRC: 1-fiber rapture; 2-fiber pull-out; 3-fiber bridging the macrocrack; 4-matrix/fiber debonding; 5-fiber counteracting crack propagation; 6-fiber bridging the microcracks.

\subsubsection{Empirical Equations for Flexural Tensile Strength}

In the literature, some formulas for the calculation of $\mathrm{f}_{\mathrm{fl}}$ of FRC can be found. Legeron and Paultre [42] suggested that $\mathrm{f}_{\mathrm{fl}}$ may be calculated by Equation (5) using the characteristic compressive strength $\mathrm{f}_{\mathrm{ck}}$ of steel FRC and the coefficient $\lambda$ being in the range of $0.35-0.65$, but usually, the value of 0.5 is assumed. This formula raises doubts, however, as it does not take into account the material, geometry and volume content of the fibers, which are used in the concrete mix, and only the $\mathrm{f}_{\mathrm{ck}}$ itself. Another suggestion is Equation (6) presented by Glinicki in $[43,44]$, also for FRC with steel fibers, which takes into account both the nominal fiber content $\left(V_{f}\right)$ and the fiber slenderness $\left(l_{f} / d_{f}\right)$. On the other hand, Swamy and Mangat [45] presented Equation (7), which not only makes $\mathrm{f}_{\mathrm{fl}}$ dependent on the properties of the metallic fiber, but also on the flexural tensile strength of concrete without fibers $\left(f_{f l c}\right)$.

$$
\begin{gathered}
\mathrm{f}_{\mathrm{fl}}=\lambda \sqrt[3]{\mathrm{f}_{\mathrm{ck}}{ }^{2}} \\
\mathrm{f}_{\mathrm{fl}}=0.73+8.061 \mathrm{~V}_{\mathrm{f}} \frac{\mathrm{l}_{\mathrm{f}}}{\mathrm{d}_{\mathrm{f}}} \\
\mathrm{f}_{\mathrm{fl}}=0.97\left(1-\mathrm{V}_{\mathrm{f}}\right) \mathrm{f}_{\mathrm{flc}}+3.41 \mathrm{~V}_{\mathrm{f}} \frac{\mathrm{l}_{\mathrm{f}}}{\mathrm{d}_{\mathrm{f}}}
\end{gathered}
$$

As can be seen, all presented formulas are given for the calculation of $\mathrm{f}_{\mathrm{fl}}$ for concrete with metallic fibers. Therefore, it was checked whether their use in the case of the tested concretes with synthetic fibers would be justified, and the results of the calculations are presented in Table 9, where $\mathrm{f}_{\mathrm{ct}, \mathrm{L}}^{\mathrm{f}}=\mathrm{f}_{\mathrm{fl}}$. 
Table 9. The flexural tensile strength of FRC calculated using empirical formulas and resulting from the tests carried out.

\begin{tabular}{|c|c|c|c|c|}
\hline Mixture & $\begin{array}{c}\mathrm{f}_{\mathrm{fl}} \text { acc. to Equation (5) } \\
{[\mathrm{MPa}]}\end{array}$ & $\begin{array}{c}\mathrm{f}_{\mathrm{fl}} \text { acc. to Equation (6) } \\
{[\mathrm{MPa}]}\end{array}$ & $\begin{array}{c}\mathrm{f}_{\mathrm{fl}} \text { acc. to Equation (7) } \\
{[\mathrm{MPa}]}\end{array}$ & $\mathrm{f}_{\mathrm{ct}, \mathrm{L}}^{\mathrm{f}}=\mathrm{f}_{\mathrm{fl}}$ from Studies $[\mathrm{MPa}]$ \\
\hline PM_3 & $7.43(2.16)$ & $3.92(1.14)$ & $4.50(1.31)$ & 3.44 \\
\hline PM_2 & $7.59(2.22)$ & $2.86(0.83)$ & 4.05 (1.18) & 3.42 \\
\hline PD_3 & $7.45(2.17)$ & $2.86(0.83)$ & 4.05 (1.18) & 3.44 \\
\hline PD_2 & $7.68(2.12)$ & $2.15(0.59)$ & $3.75(1.03)$ & 3.63 \\
\hline FF_2 & $7.70(2.08)$ & $2.78(0.75)$ & $4.02(1.09)$ & 3.69 \\
\hline
\end{tabular}

Note: the ratio of the calculated $\mathrm{f}_{\mathrm{fl}}$ from the given formula to that resulting from the performed studies is presented in the brackets.

From Table 9 it can be concluded that Equation (5) dependent only on $\mathrm{f}_{\mathrm{ck}}$ gave results more than twice higher than those obtained in the current study. Better correlation is achieved when Equation (6) was used because the obtained results were lower by 17-41\%, except for PM_3 for which they were 14\% higher than those obtained in 3PBT. On the other hand, the best agreement was obtained when Equation (7) was applied since the values of $\mathrm{f}_{\mathrm{fl}}$ were 1.03-1.31 times greater than $\mathrm{f}_{\mathrm{fl}}$ from the performed tests. Given the fact that steel fibers have a greater influence on the mechanical properties of concrete than synthetic fibers $[9,10,69]$ Equation (7) was adjusted in such a way that the concrete matrix would have a greater and the added fibers smaller influence on the calculated $\mathrm{f}_{\mathrm{fl}}$. Therefore, the authors proposed Equation (8). Table 10 compares the results obtained for the conducted research and the results included in selected literature positions with the results obtained for the empirical formula for flexural tensile strength $\mathrm{f}_{\mathrm{fl}}$ proposed by the authors. It can be concluded that Equation (8) correlated very well with the results obtained during the PM_3; PM_2; PD_3; PD_2; and FF_2 tests, as the obtained values were respectively $2.4 \% ; 0.2 \%$ greater and $0.3 \% ; 7.1 \% ; 7.3 \%$ lower than $\mathrm{f}_{\mathrm{ct}, \mathrm{L}}^{\mathrm{f}}=\mathrm{f}_{\mathrm{fl}}$. As was mentioned before, the validity of using Equation (8) was checked, when synthetic fibers of a different length, diameter, volume content and concrete mixes of various compositions included in other literature references were used. The analysis showed that the fiber content in the concrete has a significant influence on the degree of correlation. Namely, for $\mathrm{V}_{\mathrm{f}} \leq 0.5 \%$, there was usually quite a good agreement with the conducted research $\left(f_{f l}\right.$ acc. to Equation (8) $\left./ f_{f l}=0.967-1.084\right)$. Moreover, when $0.5 \% \leq V_{f} \leq 1.0 \%$, then $f_{f l}$ was from $7.2 \%$ lower to $11.3 \%$ greater than the result obtained from the performed tests. In case of higher $\mathrm{V}_{\mathrm{f}}$ the correlation was rather poor. Therefore, it can be concluded that Equation (8) can be successfully used to estimate the value of $\mathrm{f}_{\mathrm{fl}}$ when $\mathrm{V}_{\mathrm{f}} \leq 1.0 \%$. It is noteworthy that also the fiber geometry had a significant influence on the level of correlation with the proposed formula. Fibers with $\mathrm{l}_{\mathrm{f}} / \mathrm{d}_{\mathrm{f}}$ greater than 200 , i.e., equal to 480 and 600 , gave values respectively 1.17-2.55 and 1.23-1.42 times greater than the ones from the tests depending on the $V_{\mathrm{f}}$. To sum up, Equation (8) can be profitably used when the slenderness of the polymer fibers is less than 200 and $V_{\mathrm{f}} \leq 1.0 \%$ (Figure 15).

$$
\mathrm{f}_{\mathrm{fl}}=1.00\left(1-\mathrm{V}_{\mathrm{f}}\right) \mathrm{f}_{\mathrm{flc}}+0.70 \mathrm{~V}_{\mathrm{f}} \frac{\mathrm{l}_{\mathrm{f}}}{\mathrm{d}_{\mathrm{f}}}
$$

Table 10. Comparison of the results of the presented research and the results from selected literature positions with the results obtained for the empirical formula proposed by the authors for the flexural tensile strength $\mathrm{f}_{\mathrm{fl}}$.

\begin{tabular}{|c|c|c|c|c|c|c|c|}
\hline Ref. & $V_{f}[\%]$ & $\mathbf{l}_{\mathrm{f}}[\mathrm{mm}]$ & $\mathbf{d}_{\mathrm{f}}[\mathrm{mm}]$ & $1_{f} / d_{f}$ & $\mathrm{f}_{\mathrm{fl}}[\mathrm{MPa}]$ & $\begin{array}{c}f_{f l} \text { acc. to } \\
\text { Equation }(8)[\mathrm{MPa}]\end{array}$ & $\begin{array}{c}f_{\mathrm{fl}} \text { acc. to } \\
\text { Equation }(8) / f_{f l}\end{array}$ \\
\hline \multirow{6}{*}{$\begin{array}{l}\text { Presented } \\
\text { research }\end{array}$} & 0.00 & - & - & - & 3.26 & 3.26 & 1.000 \\
\hline & 0.33 & 54 & 0.45 & 120 & 3.44 & 3.52 & 1.024 \\
\hline & 0.22 & 54 & 0.45 & 120 & 3.42 & 3.43 & 1.002 \\
\hline & 0.33 & 48 & 0.60 & 80 & 3.44 & 3.43 & 0.997 \\
\hline & 0.22 & 48 & 0.60 & 80 & 3.63 & 3.37 & 0.929 \\
\hline & 0.22 & 52 & 0.45 & 115 & 3.69 & 3.43 & 0.927 \\
\hline [69] & 0.00 & - & - & - & 4.36 & 4.36 & 1.000 \\
\hline
\end{tabular}


Table 10. Cont.

\begin{tabular}{|c|c|c|c|c|c|c|c|}
\hline Ref. & $\mathrm{V}_{\mathrm{f}}[\%]$ & $\mathbf{l}_{\mathrm{f}}[\mathrm{mm}]$ & $\mathrm{d}_{\mathrm{f}}[\mathrm{mm}]$ & $1_{f} / d_{f}$ & $\mathrm{f}_{\mathrm{fl}}[\mathrm{MPa}]$ & $\begin{array}{c}f_{\mathrm{fl}} \text { acc. to } \\
\text { Equation (8) [MPa] }\end{array}$ & $\begin{array}{c}f_{f l} \text { acc. to } \\
\text { Equation }(8) / f_{f l}\end{array}$ \\
\hline & 0.30 & 50 & 0.660 & 76 & 4.64 & 4.51 & 0.971 \\
\hline & 0.33 & 50 & 0.660 & 76 & 4.54 & 4.52 & 0.997 \\
\hline \multirow[t]{5}{*}{ [10] } & 0.00 & - & - & - & 7.70 & 7.70 & 1.000 \\
\hline & 0.50 & 12 & 0.025 & 480 & 8.00 & 9.34 & 1.168 \\
\hline & 1.00 & 12 & 0.025 & 480 & 7.00 & 10.98 & 1.569 \\
\hline & 1.50 & 12 & 0.025 & 480 & 6.50 & 12.62 & 1.942 \\
\hline & 2.00 & 12 & 0.025 & 480 & 5.60 & 14.27 & 2.548 \\
\hline \multirow[t]{4}{*}{ [13] } & 0.00 & - & - & - & 3.95 & 3.95 & 1.000 \\
\hline & 0.22 & 50 & 1.000 & 50 & 3.77 & 4.02 & 1.066 \\
\hline & 0.33 & 50 & 1.000 & 50 & 3.94 & 4.05 & 1.029 \\
\hline & 0.43 & 50 & 1.000 & 50 & 3.88 & 4.08 & 1.052 \\
\hline \multirow[t]{3}{*}{ [77] } & 0.00 & - & - & - & 4.20 & 4.20 & 1.000 \\
\hline & 0.51 & 40 & $0.706^{*}$ & 57 & 4.40 & 4.38 & 0.996 \\
\hline & 0.59 & 40 & $0.706^{*}$ & 57 & 4.45 & 4.41 & 0.991 \\
\hline \multirow[t]{2}{*}{ [78] } & 0.00 & - & - & - & 5.54 & 5.54 & 1.000 \\
\hline & 0.50 & 15 & 0.100 & 150 & 5.74 & 6.04 & 1.052 \\
\hline \multirow[t]{2}{*}{ [79] } & 0.00 & - & - & - & 4.78 & 4.78 & 1.000 \\
\hline & 0.30 & 15 & 0.100 & 150 & 4.69 & 5.08 & 1.084 \\
\hline \multirow[t]{2}{*}{ [80] } & 0.00 & - & - & - & 5.21 & 5.21 & 1.000 \\
\hline & 0.50 & 20 & 0.100 & 200 & 5.61 & 5.88 & 1.049 \\
\hline \multirow[t]{3}{*}{ [68] } & 0.00 & - & - & - & 4.58 & 4.58 & 1.000 \\
\hline & 0.33 & 60 & 1.000 & 60 & 4.87 & 4.71 & 0.967 \\
\hline & 0.67 & 60 & 1.000 & 60 & 5.23 & 4.83 & 0.925 \\
\hline \multirow[t]{4}{*}{ [70] } & 0.00 & - & - & - & 2.20 & 2.20 & 1.000 \\
\hline & 0.20 & 55 & 0.850 & 65 & 2.27 & 2.29 & 1.009 \\
\hline & 0.40 & 55 & 0.850 & 65 & 2.30 & 2.37 & 1.033 \\
\hline & 0.60 & 55 & 0.850 & 65 & 2.25 & 2.46 & 1.092 \\
\hline \multirow[t]{6}{*}{ [74] } & 0.00 & - & - & - & 3.09 & 3.09 & 1.000 \\
\hline & 0.70 & 60 & 0.580 & 103 & 3.44 & 3.58 & 1.039 \\
\hline & 1.00 & 60 & 0.580 & 103 & 3.40 & 3.78 & 1.113 \\
\hline & 0.00 & - & - & - & 3.79 & 3.79 & 1.000 \\
\hline & 0.70 & 60 & 0.580 & 103 & 4.11 & 4.27 & 1.039 \\
\hline & 1.00 & 60 & 0.580 & 103 & 4.32 & 4.48 & 1.036 \\
\hline \multirow[t]{3}{*}{ [81] } & 0.00 & - & - & - & 4.73 & 4.73 & 1.000 \\
\hline & 0.32 & 40 & 0.354 * & 113 & 4.69 & 4.97 & 1.059 \\
\hline & 0.48 & 40 & 0.354 * & 113 & 4.82 & 5.09 & 1.055 \\
\hline \multirow[t]{4}{*}{ [65] } & 0.00 & - & - & - & 4.33 & 4.33 & 1.000 \\
\hline & 0.80 & 48 & 0.917 & 52 & 5.09 & 4.59 & 0.902 \\
\hline & 0.60 & 48 & 0.917 & 52 & 4.49 & 4.52 & 1.008 \\
\hline & 0.40 & 48 & 0.917 & 52 & 4.36 & 4.46 & 1.022 \\
\hline \multirow[t]{4}{*}{ [82] } & 0.00 & - & - & - & 2.62 & 2.62 & 1.000 \\
\hline & 0.15 & 12 & 0.020 & 600 & 2.64 & 3.25 & 1.230 \\
\hline & 0.30 & 12 & 0.020 & 600 & 2.84 & 3.87 & 1.363 \\
\hline & 0.50 & 12 & 0.020 & 600 & 3.32 & 4.71 & 1.418 \\
\hline \multirow[t]{6}{*}{ [47] } & 0.00 & - & - & - & 5.00 & 5.00 & 1.000 \\
\hline & 0.40 & 48 & 0.900 & 53 & 5.00 & 5.13 & 1.026 \\
\hline & 0.60 & 48 & 0.900 & 53 & 5.60 & 5.19 & 0.928 \\
\hline & 0.80 & 48 & 0.900 & 53 & 5.00 & 5.26 & 1.052 \\
\hline & 1.00 & 48 & 0.900 & 53 & 5.10 & 5.32 & 1.044 \\
\hline & 1.50 & 48 & 0.900 & 53 & 5.70 & 5.49 & 0.962 \\
\hline \multirow[t]{2}{*}{ [83] } & 0.00 & - & - & - & 5.60 & 5.60 & 1.000 \\
\hline & 0.22 & 19 & 0.095 & 200 & 5.91 & 5.90 & 0.998 \\
\hline
\end{tabular}




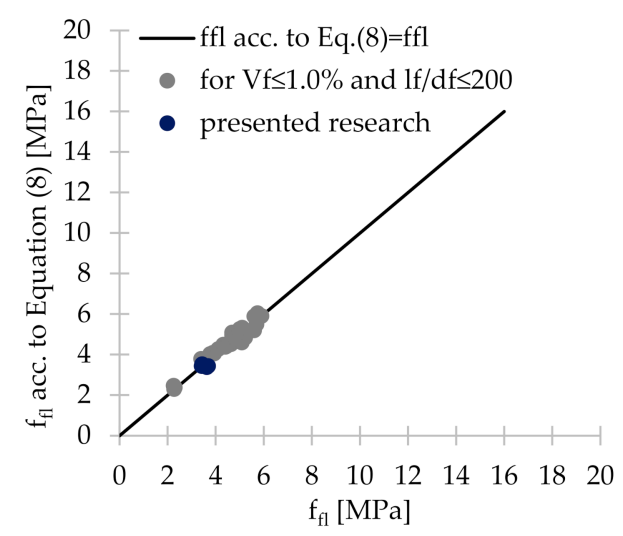

Figure 15. Graphical representation of the correlation of presented research and selected literature positions with the empirical formula for the flexural tensile strength $\mathrm{f}_{\mathrm{fl}}$ proposed by the authors.

\subsubsection{Fiber-Reinforced Concrete Classification}

Model Code 2010 [26] proposes a method of FRC classification based on the threepoint bending test carried out in accordance with the EN 14651 standard [28]. It uses the characteristic values of the limit of proportionality and residual flexural tensile strengths corresponding to CMOD $=0.5$ and $2.5 \mathrm{~mm}: \mathrm{f}_{\mathrm{ct}, \mathrm{Lk}}^{\mathrm{f}}, \mathrm{f}_{\mathrm{R}, 1 \mathrm{k}}$, and $\mathrm{f}_{\mathrm{R}, 3 \mathrm{k}}$, respectively. These values are calculated from Equation (9) and Equation (10). It is worth mentioning that $f_{R, 1 k}$ corresponds to the serviceability limit state (SLS), and $\mathrm{f}_{\mathrm{R}, 3 \mathrm{k}}$ corresponds to the ultimate limit state (ULS). The rules for classifying Parameters 1 and 2 and those regarding the possibility of total or partial replacement of traditional reinforcement in a form of steel bars by fibers are described in Table 11.

$$
\begin{aligned}
\mathrm{f}_{\mathrm{ct}, \mathrm{Lk}}^{\mathrm{f}} & =\mathrm{f}_{\mathrm{ct}, \mathrm{Lm}}^{\mathrm{f}}-\mathrm{k} \cdot \mathrm{s}_{\mathrm{ct}, \mathrm{L}}^{\mathrm{f}} \\
\mathrm{f}_{\mathrm{R}, \mathrm{jk}} & =\mathrm{f}_{\mathrm{R}, \mathrm{jm}}-\mathrm{k} \cdot \mathrm{s}_{\mathrm{R}, \mathrm{j}}
\end{aligned}
$$

where:

$\mathrm{f}_{\mathrm{ct}, \mathrm{Lk}}^{\mathrm{f}}$-characteristic limit of proportionality $\left[\mathrm{N} / \mathrm{mm}^{2}\right]$,

$\mathrm{f}_{\mathrm{ct}, \mathrm{Lm}}^{\mathrm{f}}$-mean limit of proportionality $\left[\mathrm{N} / \mathrm{mm}^{2}\right]$,

$\mathrm{f}_{\mathrm{R}, \mathrm{k}}$ - characteristic residual flexural tensile strength corresponding to $\mathrm{CMOD}=\mathrm{CMOD}_{\mathrm{j}}$ or $\delta=\delta_{j}(j=1,2,3,4)\left[\mathrm{N} / \mathrm{mm}^{2}\right]$,

$\mathrm{f}_{\mathrm{R}, \mathrm{j} m}$ - mean residual flexural tensile strength corresponding to $\mathrm{CMOD}=\mathrm{CMOD}_{\mathrm{j}}$ or $\delta=\delta_{\mathrm{j}}$ $(\mathrm{j}=1,2,3,4)\left[\mathrm{N} / \mathrm{mm}^{2}\right]$,

$\mathrm{S}_{\mathrm{ct}, \mathrm{L}}^{\mathrm{f}}$-standard deviation of $\mathrm{f}_{\mathrm{ct}, \mathrm{L}}^{\mathrm{f}}$ from $\mathrm{f}_{\mathrm{ct}, \mathrm{Lm}}^{\mathrm{f}}\left[\mathrm{N} / \mathrm{mm}^{2}\right]$ calculated from Equation (11);

$s_{R, j}$-standard deviation of $f_{R, j}$ from $f_{R, j m}\left[N / \mathrm{mm}^{2}\right]$ calculated from Equation (12)

$$
\begin{aligned}
\mathrm{s}_{\mathrm{ct}, \mathrm{L}}^{\mathrm{f}} & =\sqrt{\frac{\sum\left(\mathrm{f}_{\mathrm{ct}, \mathrm{Lm}}^{\mathrm{f}}-\mathrm{f}_{\mathrm{ct}, \mathrm{L}}^{\mathrm{f}}\right)^{2}}{(\mathrm{n}-1)}} \\
\mathrm{s}_{\mathrm{R}, \mathrm{j}} & =\sqrt{\frac{\sum\left(\mathrm{f}_{\mathrm{R}, \mathrm{m} m}-\mathrm{f}_{\mathrm{R}, \mathrm{j}}\right)^{2}}{(\mathrm{n}-1)}}
\end{aligned}
$$

where:

$\mathrm{n}$-number of samples [-],

k-factor depending on the number of samples given in Table 2 in Model Code 2010 [26], for 3 samples it is equal to 1.89 . 
Table 11. Principles of FRC classification according to Model Code 2010 [26].

\begin{tabular}{cccc}
\hline Parameter 1: & & Parameter 2: & $\begin{array}{c}\text { Total or Partial } \\
\text { Replacement of Traditional } \\
\text { Reinforcement Is Possible } \\
\text { When: }\end{array}$ \\
\hline Two consecutive & $a$ & for $0.5 \leq \mathrm{f}_{\mathrm{R}, 3 \mathrm{k}} / \mathrm{f}_{\mathrm{R}, 1 \mathrm{k}}<0.7$ & $\mathrm{f}_{\mathrm{R}, 1 \mathrm{k}} / \mathrm{f}_{\mathrm{ct}, \mathrm{Lk}}^{\mathrm{f}}>0.4$ and \\
$\mathrm{f}_{\mathrm{R}, 3 \mathrm{k}} / \mathrm{f}_{\mathrm{R}, 1 \mathrm{k}}>0.5$ \\
numbers in series $1.0 ; 1.5 ;$ & $b$ & for $0.7 \leq \mathrm{f}_{\mathrm{R}, 3 \mathrm{k}} / \mathrm{f}_{\mathrm{R}, 1 \mathrm{k}}<0.9$ & \\
$2.0 ; 2.5 ; 3.0 ; 4.0 ; 5.0 ; 6.0 ;$ & $c$ & for $0.9 \leq \mathrm{f}_{\mathrm{R}, 3 \mathrm{k}} / \mathrm{f}_{\mathrm{R}, 1 \mathrm{k}}<1.1$ & \\
$7.0 ; 8.0 ; \ldots[\mathrm{MPa}]$ define & $d$ & for $1.1 \leq \mathrm{f}_{\mathrm{R}, 3 \mathrm{k}} / \mathrm{f}_{\mathrm{R}, 1 \mathrm{k}}<1.3$ & \\
the strength range $\mathrm{f}_{\mathrm{R}, 1 \mathrm{k}}$. & $e$ & for $1.3 \leq \mathrm{f}_{\mathrm{R}, 3 \mathrm{k}} / \mathrm{f}_{\mathrm{R}, 1 \mathrm{k}}$ & \\
\hline
\end{tabular}

Table 12 presents the results of the FRC classification according to Model Code 2010 [26]. Firstly, only for FF_2 it was possible to assign the mix to Parameter 1 which was equal to 1.0. For the remaining series, all values of $f_{R, 1 \mathrm{k}}$ were smaller than 1.0. Additionally, only for the mixtures PM_3 and PD_2 the ratio $f_{R, 3 k} / f_{R, 1 k}$ was greater than 0.5 , so it is possible to assign them to letters $c$ and $a$ of Parameter 2, respectively. It is also not possible to completely or partially replace the traditional reinforcement with the fibers, as none of the concrete met the two above-mentioned requirements simultaneously: $\mathrm{f}_{\mathrm{R}, 1 \mathrm{k}} / \mathrm{f}_{\mathrm{ct}, \mathrm{Lk}}^{\mathrm{f}}>0.4$ and $f_{R, 3 k} / f_{R, 1 k}>0.5$. It is also worth mentioning that the characteristic values of the residual strengths were significantly reduced as a result of the large standard deviation $\left(S_{\mathrm{ct}, \mathrm{L}}^{\mathrm{f}}\right.$ and $\mathrm{S}_{\mathrm{R}, \mathrm{j}}$ ) between samples in a given series. In future tests, it is advisable to increase the number of samples within each mixture. Furthermore, concrete mixes with different amounts of cement, coarse and fine aggregate, water and superplasticizer should be tested to verify made conclusions.

Table 12. FRC classification according to Model Code 2010 [26].

\begin{tabular}{|c|c|c|c|c|c|c|c|c|}
\hline \multicolumn{9}{|c|}{ PM_3 } \\
\hline $\mathrm{f}_{\mathrm{ct}, \mathrm{Lm}}^{\mathrm{f}}[\mathrm{MPa}]$ & 3.44 & $\mathrm{~S}_{\mathrm{ct}, \mathrm{L}}^{\mathrm{f}}[\mathrm{MPa}]$ & 0.37 & $\mathrm{k}$ & 1.89 & $\mathrm{f}_{\mathrm{ct}, \mathrm{Lk}}^{\mathrm{f}}[\mathrm{MPa}]$ & 2.74 & $\mathrm{f}_{\mathrm{R}, 3 \mathrm{k}} / \mathrm{f}_{\mathrm{R}, 1 \mathrm{k}} 0.95$ \\
\hline $\mathrm{f}_{\mathrm{R}, 1 \mathrm{~m}}[\mathrm{MPa}]$ & 1.52 & $\mathrm{~s}_{\mathrm{R}, 1}[\mathrm{MPa}]$ & 0.61 & & 1.89 & $\mathrm{f}_{\mathrm{R}, 1 \mathrm{k}}[\mathrm{MPa}]$ & 0.36 & $\mathrm{f}_{\mathrm{R}, \mathrm{k}} / \mathrm{f}_{\mathrm{ct} \mathrm{Lk}}^{\mathrm{f}} 0.13$ \\
\hline $\mathrm{f}_{\mathrm{R}, 3 \mathrm{~m}}[\mathrm{MPa}]$ & 1.05 & $\mathrm{~s}_{\mathrm{R}, 3}[\mathrm{MPa}]$ & 0.38 & & 1.89 & $\mathrm{f}_{\mathrm{R}, 3 \mathrm{k}}[\mathrm{MPa}]$ & 0.34 & \\
\hline \multicolumn{9}{|c|}{ PM_2 } \\
\hline $\mathrm{f}_{\mathrm{ct}, \mathrm{Lm}}^{\mathrm{f}}[\mathrm{MPa}]$ & 3.42 & $\mathrm{~S}_{\mathrm{ct}, \mathrm{L}}^{\mathrm{f}}[\mathrm{MPa}]$ & 0.42 & $\mathrm{k}$ & 1.89 & $\mathrm{f}_{\mathrm{ct} \text { Lk }}^{\mathrm{f}}[\mathrm{MPa}]$ & 2.64 & $\mathrm{f}_{\mathrm{R}, 3 \mathrm{k}} / \mathrm{f}_{\mathrm{R}, 1 \mathrm{k}} \quad 0.43$ \\
\hline $\mathrm{f}_{\mathrm{R}, 1 \mathrm{~m}}[\mathrm{MPa}]$ & 1.07 & $\mathrm{~s}_{\mathrm{R}, 1}[\mathrm{MPa}]$ & 0.20 & & 1.89 & $\mathrm{f}_{\mathrm{R}, 1 \mathrm{k}}[\mathrm{MPa}]$ & 0.68 & $\mathrm{f}_{\mathrm{R}, 1 \mathrm{k}} / \mathrm{f}_{\mathrm{ct}, \mathrm{Lk}}^{\mathrm{f}} 0.26$ \\
\hline $\mathrm{f}_{\mathrm{R}, 3 \mathrm{~m}}[\mathrm{MPa}]$ & 0.67 & $\mathrm{~s}_{\mathrm{R}, 3}[\mathrm{MPa}]$ & 0.20 & & 1.89 & $\mathrm{f}_{\mathrm{R}, 3 \mathrm{k}}[\mathrm{MPa}]$ & 0.30 & \\
\hline \multicolumn{9}{|c|}{ PD_3 } \\
\hline $\mathrm{f}_{\mathrm{ct}, \mathrm{Lm}}^{\mathrm{f}}[\mathrm{MPa}]$ & 3.44 & $\mathrm{~S}_{\mathrm{ct}, \mathrm{L}}^{\mathrm{f}}[\mathrm{MPa}]$ & 0.31 & $\mathrm{k}$ & 1.89 & $\mathrm{f}_{\mathrm{ct}, \mathrm{Lk}}^{\mathrm{f}}[\mathrm{MPa}]$ & 2.86 & $\mathrm{f}_{\mathrm{R}, 3 \mathrm{k}} / \mathrm{f}_{\mathrm{R}, 1 \mathrm{k}} \quad 0.13$ \\
\hline $\mathrm{f}_{\mathrm{R}, 1 \mathrm{~m}}[\mathrm{MPa}]$ & 1.16 & $\mathrm{~s}_{\mathrm{R}, 1}[\mathrm{MPa}]$ & 0.25 & & 1.89 & $\mathrm{f}_{\mathrm{R}, 1 \mathrm{k}}[\mathrm{MPa}]$ & 0.69 & $\mathrm{f}_{\mathrm{R}, 1 \mathrm{k}} / \mathrm{f}_{\mathrm{ct}, \mathrm{k}}^{\mathrm{f}} 0.24$ \\
\hline $\mathrm{f}_{\mathrm{R}, 3 \mathrm{~m}}[\mathrm{MPa}]$ & 0.93 & $\mathrm{~s}_{\mathrm{R}, 3}[\mathrm{MPa}]$ & 0.44 & & 1.89 & $\mathrm{f}_{\mathrm{R}, 3 \mathrm{k}}[\mathrm{MPa}]$ & 0.09 & \\
\hline \multicolumn{9}{|c|}{ PD_2 } \\
\hline $\mathrm{f}_{\mathrm{ct}, \mathrm{Lm}}^{\mathrm{f}}[\mathrm{MPa}]$ & 3.63 & $\mathrm{~S}_{\mathrm{ct}, \mathrm{L}}^{\mathrm{f}}[\mathrm{MPa}]$ & 0.10 & $\mathrm{k}$ & 1.89 & $\mathrm{f}_{\mathrm{ct}, \mathrm{Lk}}^{\mathrm{f}}[\mathrm{MPa}]$ & 3.43 & $\mathrm{f}_{\mathrm{R}, 3 \mathrm{k}} / \mathrm{f}_{\mathrm{R}, 1 \mathrm{k}} \quad 0.66$ \\
\hline $\mathrm{f}_{\mathrm{R}, 1 \mathrm{~m}}[\mathrm{MPa}]$ & 1.97 & $\mathrm{~s}_{\mathrm{R}, 1}[\mathrm{MPa}]$ & 0.71 & & 1.89 & $\mathrm{f}_{\mathrm{R}, 1 \mathrm{k}}[\mathrm{MPa}]$ & 0.63 & $\mathrm{f}_{\mathrm{R}, 1 \mathrm{k}} / \mathrm{f}_{\mathrm{ctLk}}^{\mathrm{f}} 0.18$ \\
\hline $\mathrm{f}_{\mathrm{R}, 3 \mathrm{~m}}[\mathrm{MPa}]$ & 0.73 & $\mathrm{~s}_{\mathrm{R}, 3}[\mathrm{MPa}]$ & 0.16 & & 1.89 & $\mathrm{f}_{\mathrm{R}, 3 \mathrm{k}}[\mathrm{MPa}]$ & 0.42 & \\
\hline \multicolumn{9}{|c|}{ FF_2 } \\
\hline $\mathrm{f}_{\mathrm{ct}, \mathrm{Lm}}^{\mathrm{f}}[\mathrm{MPa}]$ & 3.69 & $\mathrm{~S}_{\mathrm{ct}, \mathrm{L}}^{\mathrm{f}}[\mathrm{MPa}]$ & 0.11 & $\mathrm{k}$ & 1.89 & $\mathrm{f}_{\mathrm{ct}, \mathrm{Lk}}^{\mathrm{f}}[\mathrm{MPa}]$ & 3.48 & $\mathrm{f}_{\mathrm{R}, 3 \mathrm{k}} / \mathrm{f}_{\mathrm{R}, 1 \mathrm{k}} \quad 0.39$ \\
\hline $\mathrm{f}_{\mathrm{R}, 1 \mathrm{~m}}[\mathrm{MPa}]$ & 1.21 & $\mathrm{~s}_{\mathrm{R}, 1}[\mathrm{MPa}]$ & 0.04 & & 1.89 & $\mathrm{f}_{\mathrm{R}, 1 \mathrm{k}}[\mathrm{MPa}]$ & 1.14 & $\mathrm{f}_{\mathrm{R}, 1 \mathrm{k}} / \mathrm{f}_{\mathrm{ct}, \mathrm{fk}}^{\mathrm{f}} 0.33$ \\
\hline $\mathrm{f}_{\mathrm{R}, 3 \mathrm{~m}}[\mathrm{MPa}]$ & 0.81 & $\mathrm{~s}_{\mathrm{R}, 3}[\mathrm{MPa}]$ & 0.19 & & 1.89 & $\mathrm{f}_{\mathrm{R}, 3 \mathrm{k}}[\mathrm{MPa}]$ & 0.45 & \\
\hline
\end{tabular}

\subsection{Fracture Energy and Toughness}

The area under the F-CMOD curve is called the fracture energy-toughness ( $\left.\mathrm{G}_{\mathrm{F}-\mathrm{CMOD}}\right)$. In the article, this area is counted up to $\mathrm{CMOD}=3.5 \mathrm{~mm}$. Figure 16 shows a graph of the mean fracture energies $\left(\mathrm{G}_{\mathrm{F}-\mathrm{CMOD}=3.5}\right)$ calculated for all three specimens within each mixture. 
It can be concluded that specimens with more fibers performed best. The calculated toughness index $\mathrm{T}_{\mathrm{i}}$, which is equal to the ratio of $\mathrm{G}_{\mathrm{F}-\mathrm{CMOD}=3.5}$ for $\mathrm{FRC}$ to $\mathrm{G}_{\mathrm{F}-\mathrm{CMOD}=3.5}$ for PC samples, indicates that the fracture energy for PM_3 and PD_3 increased 22 and 19.6 times, respectively (Table 13). On the other hand, among the mixtures with $V_{\mathrm{f}}=2 \mathrm{~kg} / \mathrm{m}^{3}$, the best results were achieved for samples FF_2, where a hybrid blend was used. Compared to other studies in the literature such as [76,77], for similar or higher macrofibers contents in the mix, the ratio of $\mathrm{G}_{\mathrm{F}-\mathrm{CMOD}}$ of plain concrete to $\mathrm{G}_{\mathrm{F}-\mathrm{CMOD}}$ of FRC was much lower. There are also studies [80] where microfibers with $\mathrm{V}_{\mathrm{f}}=0.50 \%$ were used, and the $\mathrm{G}_{\mathrm{F}-\mathrm{CMOD}}$ value was two times lower than the fracture energy presented in this article, despite the higher fiber content. However, it is related to the fact that shorter fibers have a greater influence when concrete is in the initial stage of flexural tensile test, so up to the point of crack formation. It is because they more effectively bridge the smaller cracks and their amount in the concrete mixture is higher. Moreover, in [71] for lightweight concretes with the addition of slightly shorter polypropylene fibers with $\mathrm{l}_{\mathrm{f}} / \mathrm{d}_{\mathrm{f}}=38 \mathrm{~mm} / 0.91 \mathrm{~mm}$ but with higher $\mathrm{V}_{\mathrm{f}}=0.5 ; 0.7 ; 0.9 ; 1.1 ; 1.3 \%$ similar values of $\mathrm{G}_{\mathrm{F}-\mathrm{CMOD}}=13.88 ; 16.60 ; 18 ; 13 ; 23.26$; 18.27 Nm, respectively, were obtained. All this indicates the logicality of the obtained results for the PC, PM_3, PM_2, PD_3, PD_2 and FF_2.

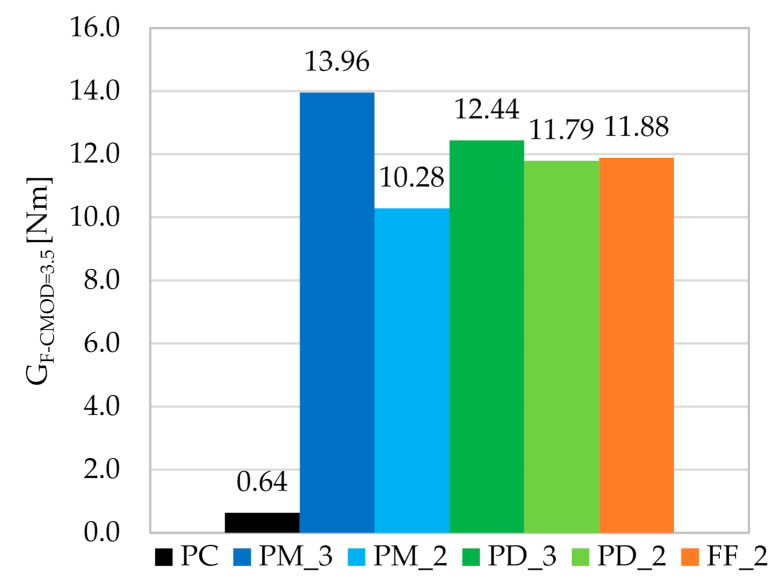

Figure 16. The mean fracture energy calculated up to $\mathrm{CMOD}=3.5 \mathrm{~mm}$ for individual concrete mixes.

Table 13. Standard deviation, coefficient of variation of fracture energy and toughness index for individual concrete mixes.

\begin{tabular}{|c|c|c|c|c|c|c|}
\hline Parameter & PC & PM_3 & PM_2 & PD_3 & PD_2 & FF_2 \\
\hline $\mathrm{s}_{\mathrm{GF}-\mathrm{CMOD}=3.5}[\mathrm{Nm}]$ & 0.18 & 4.27 & 2.89 & 4.54 & 1.38 & 1.73 \\
\hline $\mathrm{V}_{\mathrm{GF}-\mathrm{CMOD}=3.5[\%]}$ & $27.56 \%$ & $30.58 \%$ & $28.10 \%$ & $36.50 \%$ & $11.75 \%$ & $14.56 \%$ \\
\hline $\mathrm{T}_{\mathrm{i}}[-]$ & 1.0 & 21.97 & 16.19 & 19.59 & 18.56 & 18.71 \\
\hline
\end{tabular}

A significant increase in the level of fracture energy absorption indicates the positive effect of synthetic fibers on the ductility of concrete, which makes it possible to avoid sudden, brittle failure of the FRC element. In addition, the greater the fiber content, the greater

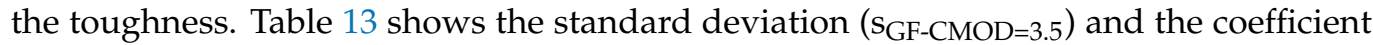
of variation $\left(\mathrm{V}_{\mathrm{GF}-\mathrm{CMOD}=3.5}\right)$ of the fracture energy. All the mixtures were characterized by quite high $\mathrm{s}_{\mathrm{GF}-\mathrm{CMOD}=3.5}$ and $\mathrm{V}_{\mathrm{GF}-\mathrm{CMOD}=3.5}$, which is also visible in Figure 10. In order to investigate the cause of such a large discrepancy between the samples, each beam was broken and photographed in the crack cross-section. Figure 17 presents three samples of the mixture PM_3 (PM_3_1, PM_3_2, PM_3_3) and PD_3 (PD_3_1, PD_3_2, PD_3_3) with the largest $\mathrm{S}_{\mathrm{GF}-\mathrm{CMOD}=3.5}$. In the case of the PM_3 mix, it was noticeable that some of the twisted fibers did not disintegrate, which influenced the distribution of the fibers in the crack cross-section and make it uneven. In order to avoid this situation in the future, the fibers should be added at the initial stage along with aggregates so that they have the pos- 
sibility of breaking the bundles of fibers. A similar situation occurred in the case of PM_2. On the other hand, in the PD_3 mixture, there was no tendency to create bundles of fibers and the PD_2 mixture was characterized by the lowest $\mathrm{V}_{\mathrm{GF}-\mathrm{CMOD}=3.5}$. Thus, the reason for such large differences in $\mathrm{G}_{\mathrm{F}-\mathrm{CMOD}=3.5}$ in PD_3 may be connected with a significantly different number of fibers in the crack cross-section. It is noteworthy that the F-CMOD plot for the sample PD_3_3 clearly differed from F-CMOD plots for PD_3_1 and PD_3_2 and took much larger force values for the same values of CMOD. Additionally, by comparing Figure $17 \mathrm{~d}-\mathrm{f}$ it can be seen that the latter shows a greater amount of fibers in the failure cross-section. In order to verify this conclusion more precisely, it would be necessary to count the fibers in the crack cross-section for all PD_3 samples and compare them.

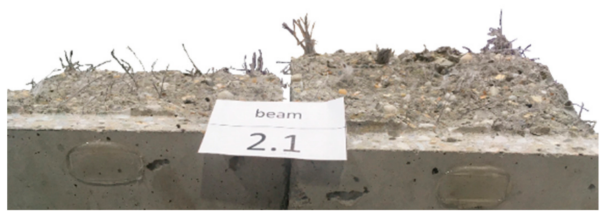

(a)

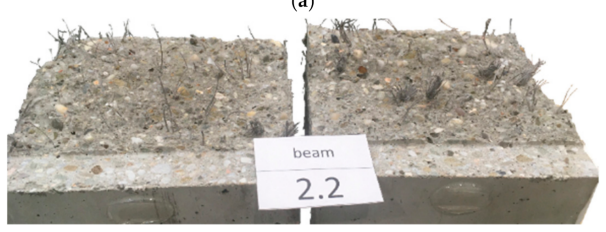

(b)

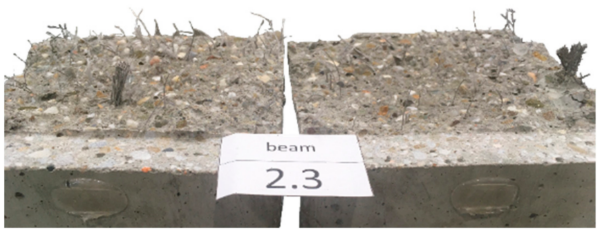

(c)
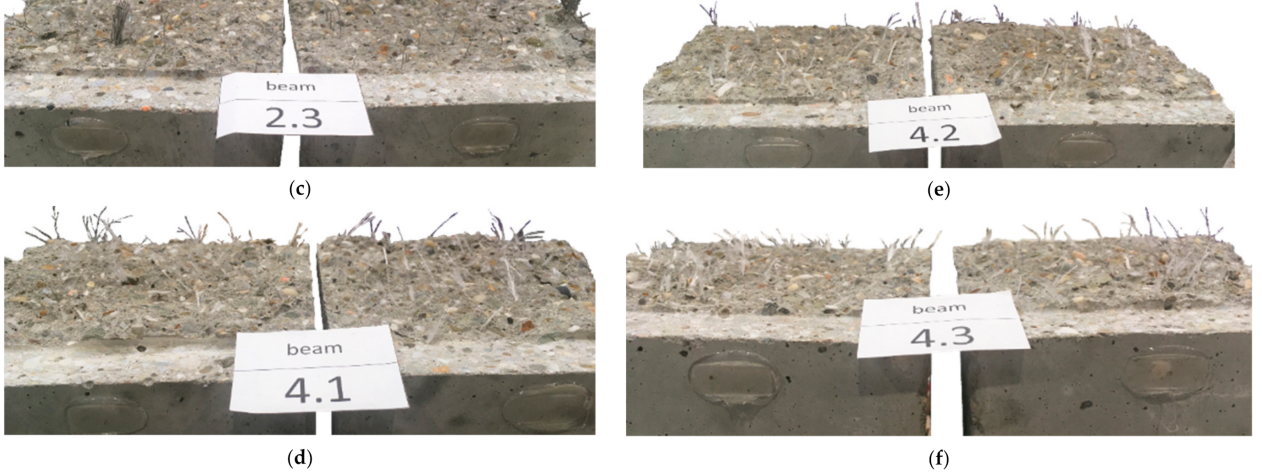

(d)

Figure 17. FRC beams broken in the crack cross-section: (a) PM_3_1; (b) PM_3_2; (c) PM_3_3; (d) PD_3_1; (e) PD_3_2; (f) PD_3_3.

\subsection{Tensile Strength}

The results of the maximum tensile strength $\mathrm{f}_{\mathrm{t}}$ obtained during the UTT are presented in Figure 18. It can be concluded that the addition of fibers did not have a clear influence on $\mathrm{f}_{\mathrm{t}}$. Despite PM_3 and FF_2, the samples had lower strength by around $11.5 \%$. On the other hand, the small effect of $V_{f}$ is visible, since mixes with $3 \mathrm{~kg} / \mathrm{m}^{3}$ behaved better than the ones with $2 \mathrm{~kg} / \mathrm{m}^{3}$ of the same fibers. Additionally, the hybrid mixture had $\mathrm{f}_{\mathrm{t}} 2.6 \%$ higher than the mix with no fibers. As was seen before, FF_2 performed usually better than other concrete mixtures with $2 \mathrm{~kg} / \mathrm{m}^{3}$ of fibers. In future research, a higher number of tested samples should be used to limit the influence of different amounts of fibers in the cracked cross-section within one mixture. 


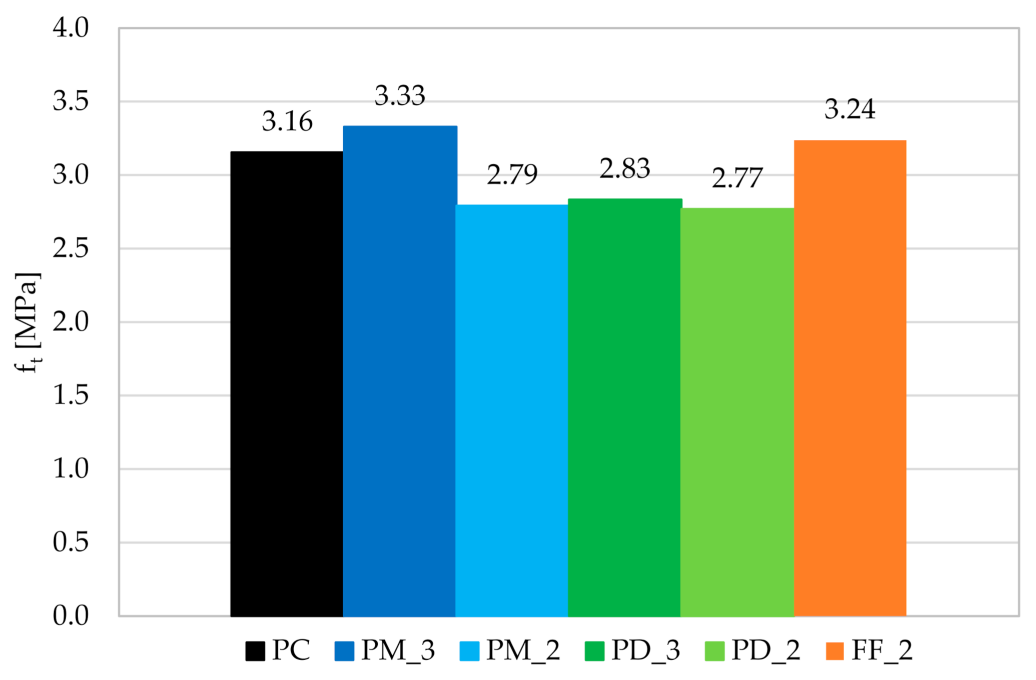

Figure 18. Graph of the mean tensile strength for individual concrete mixes.

In the case of plain concrete, it was not expected to obtain $\sigma$-w curve since brittle failure was predicted. On the other hand, studied FRC were supposed to behave in a more ductile way. However, for none of them $\sigma-w$ curve was received because the failure was really sudden. In Figure 19, cracking of PM_2 dog-bone specimen can be seen during a tensile test, where the time difference between taking pictures was equal to less than $0.02 \mathrm{sec}$. Moreover, it must be mentioned that four from six samples (PM_3; PD_3; PD_2; FF_2) cracked in the place out of measured range, where the stirrups ended. The reason for not obtaining the $\sigma-\mathrm{w}$ curve may be connected with a relatively small amount of fibers and/or flaws of the set-up, for example manual application of tensile force without a constant increase.
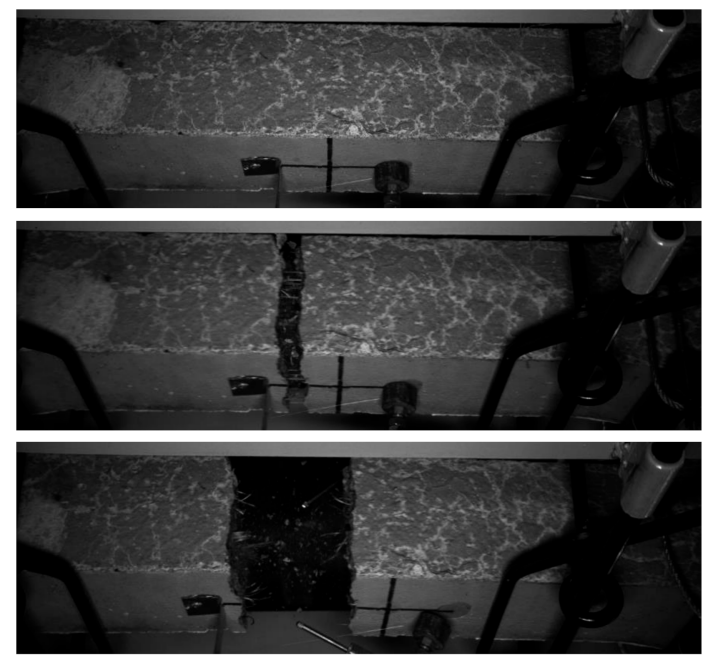

Figure 19. Cracking of PM_2 dog-bone specimen during the tensile test.

\subsection{CMOD- $\delta, C M O D-C T O D$ and $C T O D-\delta$}

During the three-point bending test, apart from CMOD measurements, the corresponding CTOD and $\delta$ were also measured. Thanks to this, it was possible to determine the relationship between them and Figure 20 shows the first one: CMOD- $\delta$. From Figure 20, it can be concluded that for all concrete mixes tested in the research, the CMOD- $\delta$ plots were very similar. Therefore, the mean of the five FRC series was calculated, and then Equation (13) was determined, which correlated very well with this mean $\left(R^{2}=0.999\right)$. Figure 20 also shows the line representing Equation (1), which describes the relationship between CMOD and $\delta$ contained in the EN 14651 standard [28]. As can be seen, it differs from 
the lines determined for FRC mixtures and correlates with them worse than Equation (13) proposed by the authors. Then, in Figure 21, CMOD-CTOD plots are visible, which practically overlap each other. As in the case of CMOD- $\delta$, the formula of the line describing the mean CMOD-CTOD $\left(\mathrm{R}^{2}=0.998\right)$ was determined (Equation (14)). For the CTOD- $\delta$ relationship (Figure 22) the procedure algorithm was the same as for CMOD-CTOD and the formula proposed by the authors is marked as Equation (15). Equations (13)-(15) can be used to calculate $\delta, \mathrm{CMOD}$ and/or CTOD when only one of the values is measured during the three-point bending test. Additionally, it is worth noting that all the discussed relationships are linear and directly proportional.

$$
\begin{gathered}
\delta=0.734 \mathrm{CMOD}+0.0065 \\
\text { CTOD }=0.7685 \mathrm{CMOD}+0.0523 \\
\delta=0.954 \mathrm{CTOD}-0.0434
\end{gathered}
$$

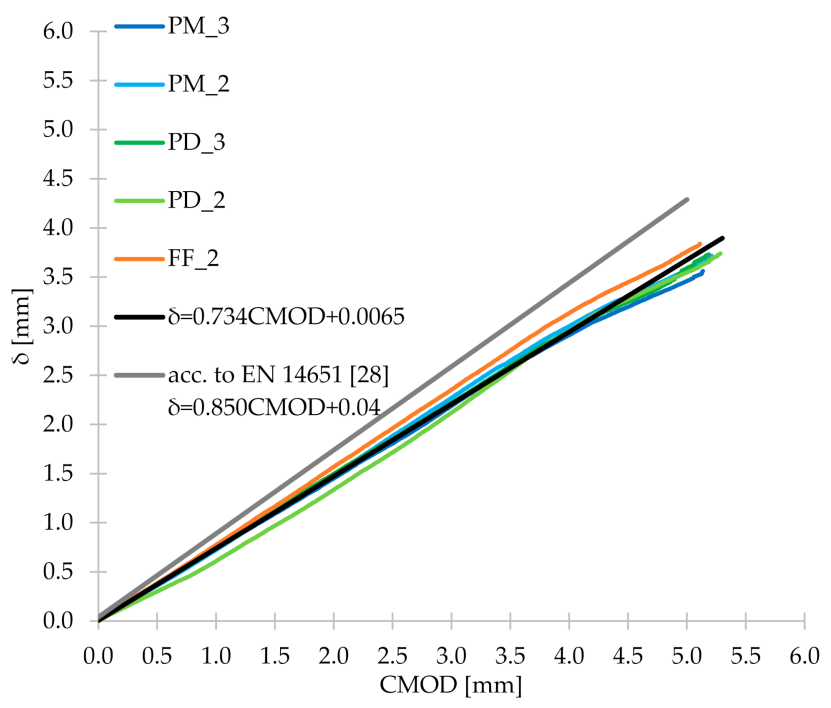

Figure 20. CMOD- $\delta$ diagram for the tested concrete mixes with the formula described in EN 14651 [28] and Equation (13) proposed by the authors.

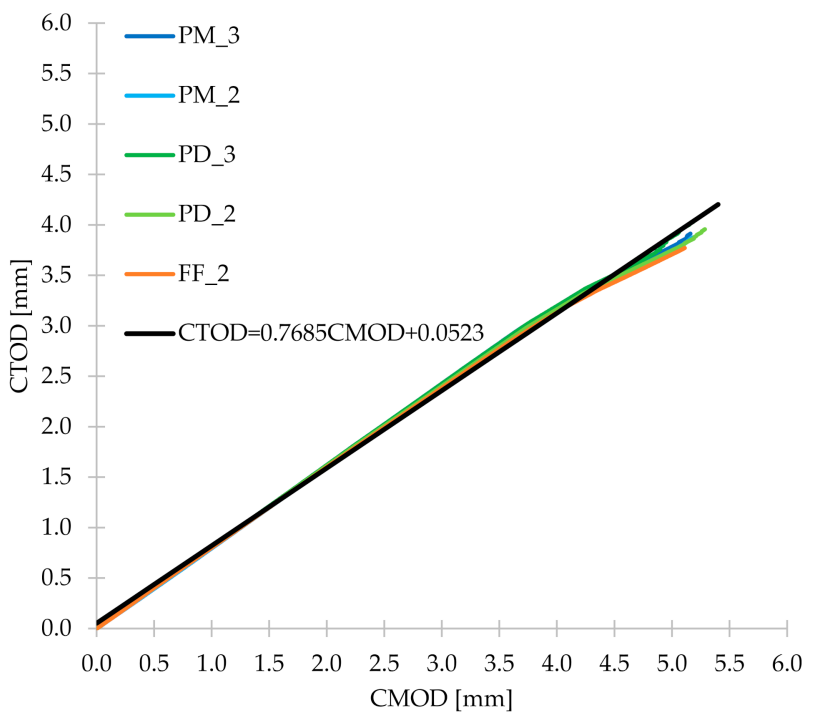

Figure 21. CMOD-CTOD diagram for the tested concrete mixes together with Equation (14) proposed by the authors. 


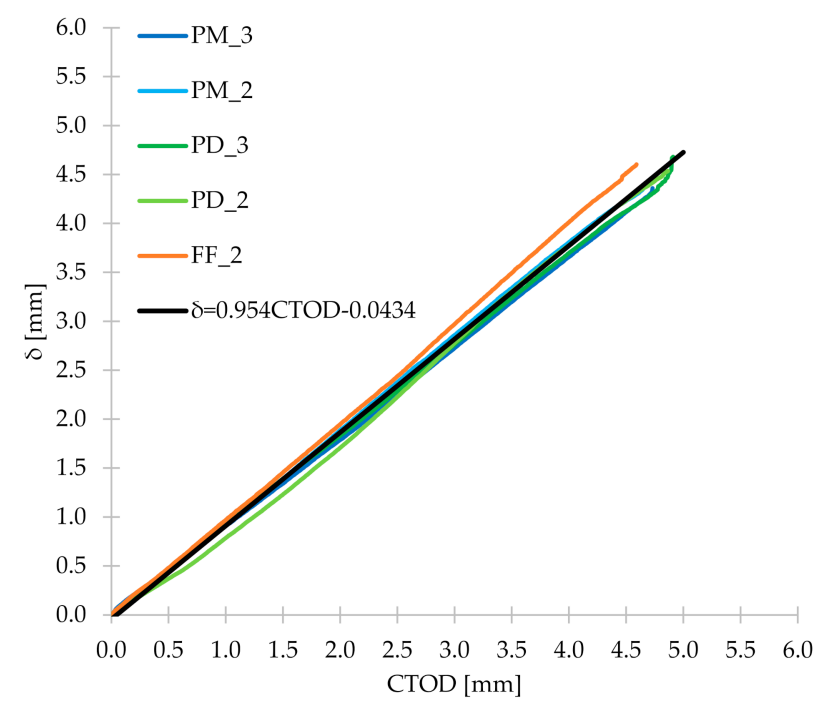

Figure 22. CTOD- $\delta$ diagram for the tested concrete mixes together with Equation (15) proposed by the authors.

\subsection{Digital Image Correlation}

The purpose of carrying out the DIC technique was to compare the values obtained from clip gauges with CMOD and CTOD measurements from optical system and to visualize the crack propagation and to analyze the strains. Firstly, all 15 specimens (only FRC samples) were subjected to the DIC post-processing analyzes in the GOM Correlate 2020 software. Then, the CMOD and CTOD values were read from the program and together with the results from clip gauges plotted in the relevant figures together with corresponding F. Figure 23 presents the comparison of F-CMOD and F-CTOD curves for some of the samples (PM_3_2; PD_3_2; FF_2_3). Additionally, on the left side of Figure 23, the localization of CMOD and CTOD measurements in the software is shown. It can be concluded that comparing F-CMOD and F-CTOD, better correlation is achieved for CTOD and curves overlapping each other almost perfectly. The CMOD fit is also very good, however in the phase after the crack occurrence, some small shifts are observed. This can be due to the fact that CMOD in the DIC system was measured in the place not exactly corresponding with the localization of the clip gauge position, and with the increasing value of $\mathrm{CMOD}$, the error is higher and more visible. Nevertheless, the fit accuracy for both CMOD and CTOD presented in Figure 23 and the rest of the specimens was almost perfect. It can be concluded then that the DIC technique can successfully replace and/or support the traditional methods for measuring the displacements during 3PBT. Additionally, in Table 15 the crack propagation and $\varepsilon_{\mathrm{x}}$ strain maps are presented for selected CMOD, corresponding with $\mathrm{f}_{\mathrm{ct}, \mathrm{L}}^{\mathrm{f}}$ and $\mathrm{f}_{\mathrm{R}, 1}-\mathrm{f}_{\mathrm{R}, 4}$. It is easily visible that the crack propagation developed within increasing $\mathrm{F}$ and $\mathrm{CMOD}$. The conclusion mentioned before that the beams were destroyed by a quasi-vertical crack beginning in the sample notch is also confirmed by the DIC technique. When it comes to strain maps, only for small CMOD up to $0.5 \mathrm{~mm}$ the horizontal strains could have been noticed in the images. When the crack width was increasing, two parts of the sample were detaching from each other, making the camera not able to recognize the speckle pattern. 

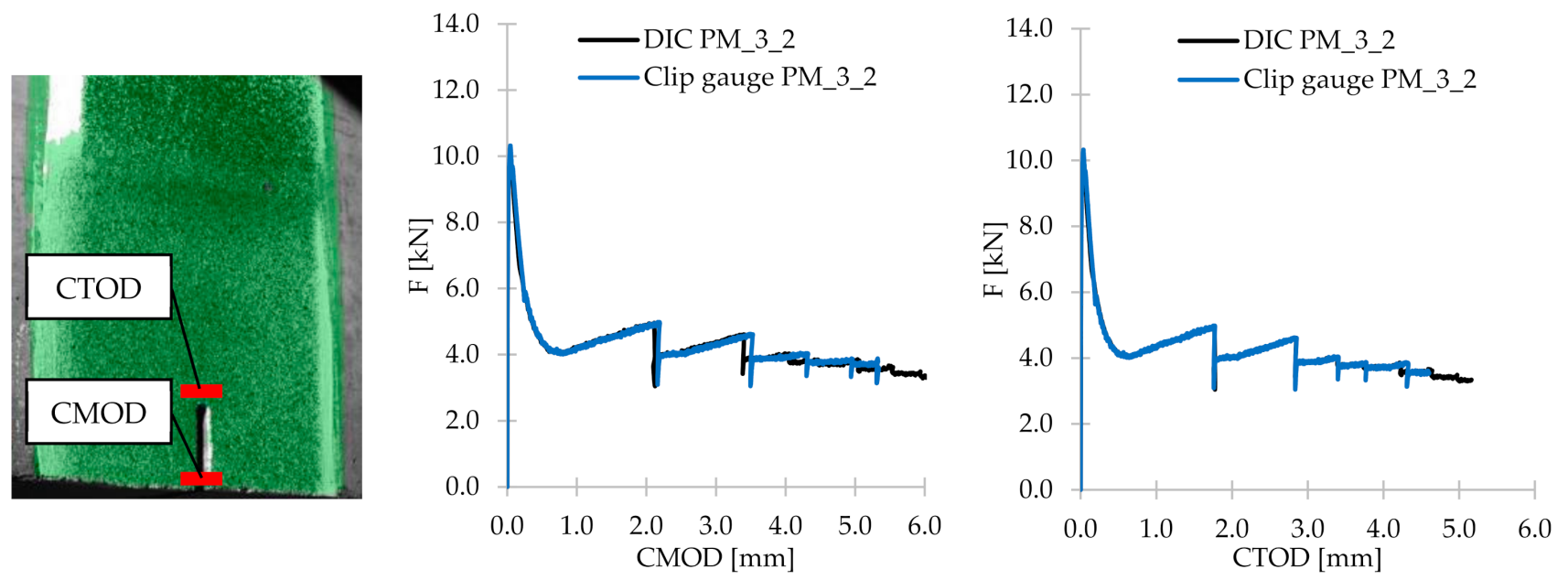

(a)
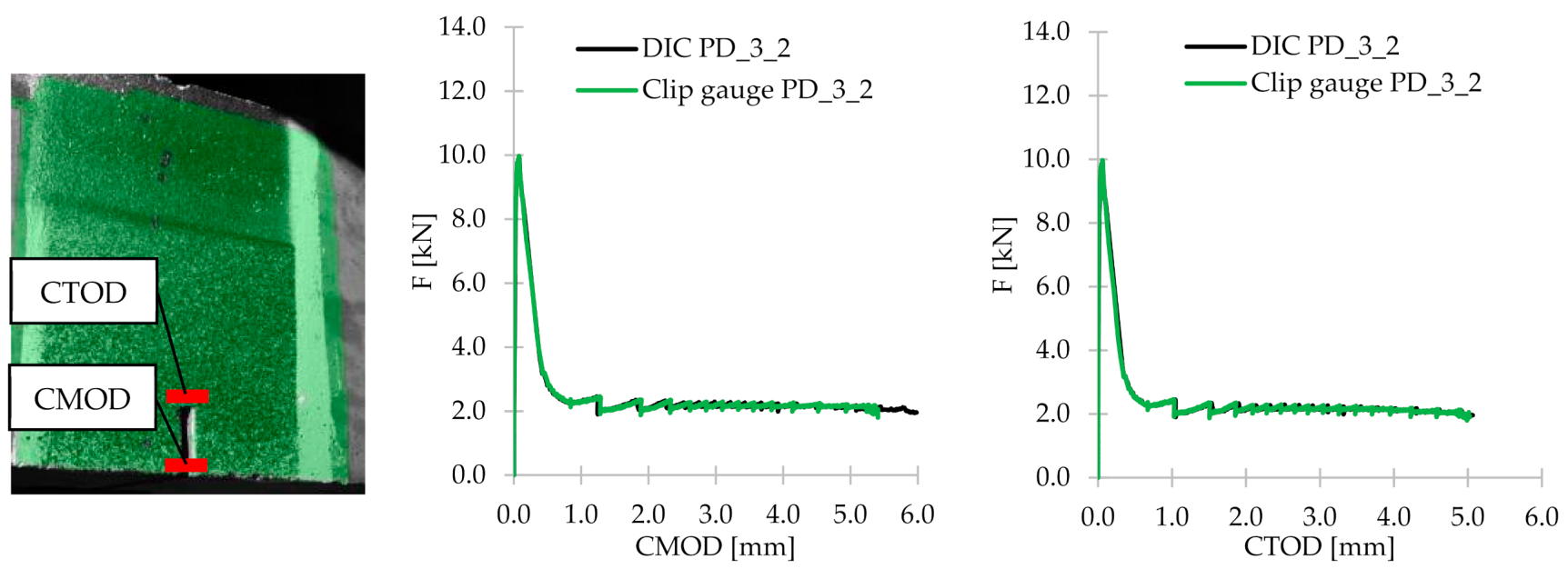

(b)
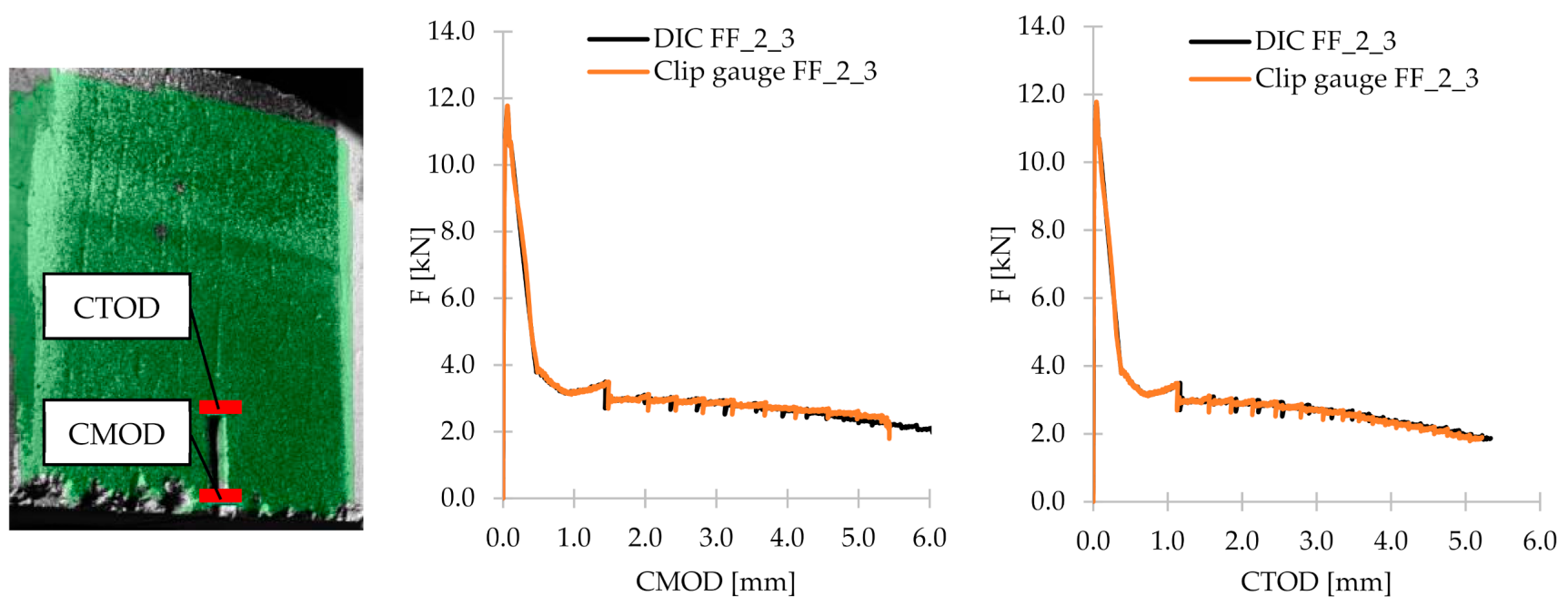

(c)

Figure 23. Comparison of CMOD and CTOD results from clip gauges and the DIC system for selected samples: (a) PM_3_2; (b) PD_3_2; (c) FF_2_3. 
Table 14. Comparison of $\varepsilon_{\mathrm{x}}$ strain maps and crack propagation in FRC beams at considered CMOD.

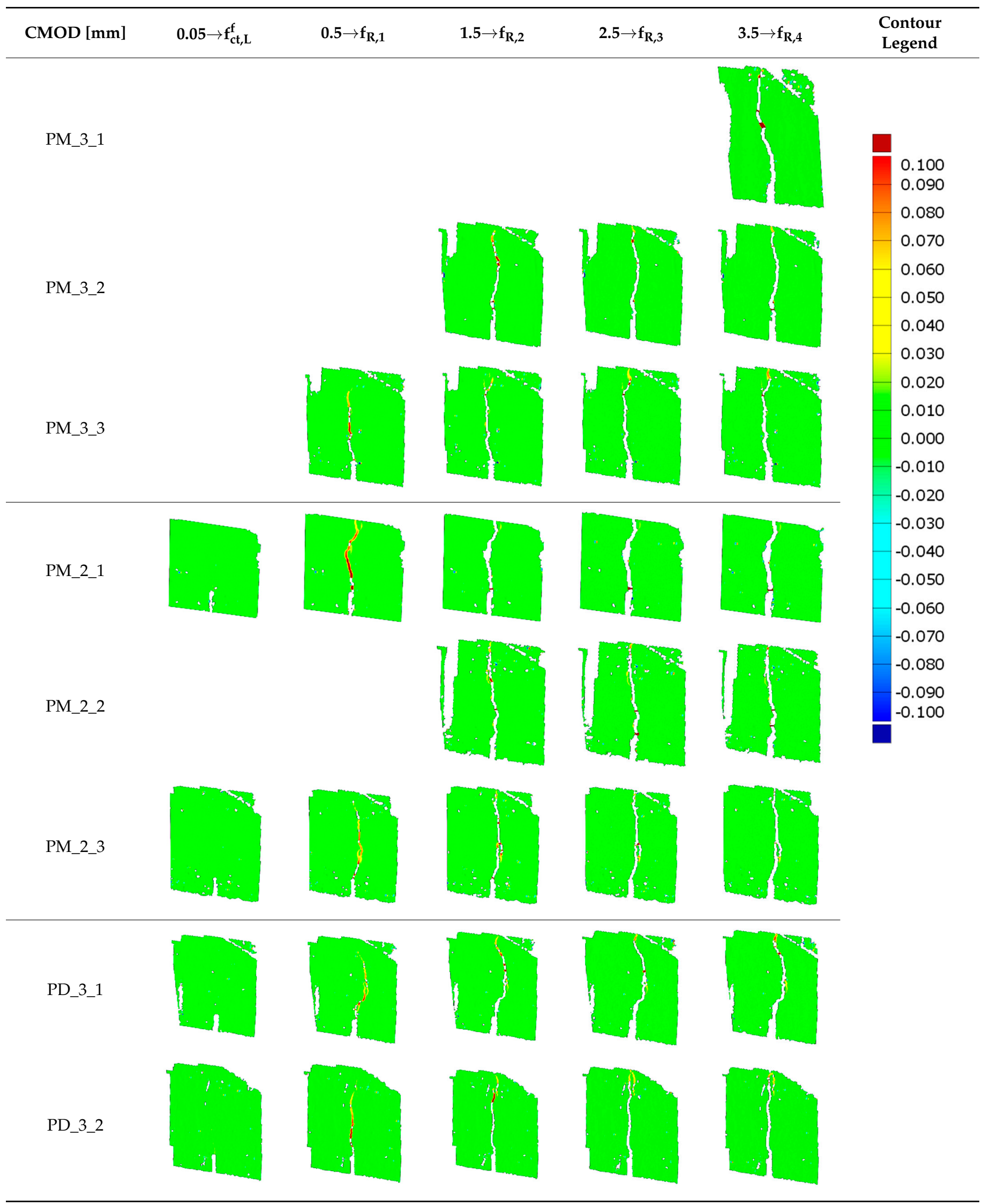


Table 15. Cont.

\begin{tabular}{|c|c|c|c|c|c|c|}
\hline CMOD [mm] & $0.05 \rightarrow \mathrm{f}_{\mathrm{ct}, \mathrm{L}}^{\mathrm{f}}$ & $0.5 \rightarrow \mathbf{f}_{\mathbf{R}, 1}$ & $1.5 \rightarrow \mathbf{f}_{\mathbf{R}, 2}$ & $2.5 \rightarrow \mathbf{f}_{\mathrm{R}, 3}$ & $3.5 \rightarrow \mathbf{f}_{\mathrm{R}, 4}$ & $\begin{array}{l}\text { Contour } \\
\text { Legend }\end{array}$ \\
\hline PD_3_3 & & & & & & \\
\hline PD_2_1 & & & & & & \\
\hline PD_2_2 & & & & & & \\
\hline PD_2_3 & & & & & & \\
\hline FF_2_1 & & & & & & \\
\hline FF_2_2 & & & & & & \\
\hline FF_2_3 & & & & & & \\
\hline
\end{tabular}

Note: Empty cells in the table are due to the fact that in some stages the software was not able to process the data.

\section{Conclusions}

The article presents the possibility of using the EN 14651 standard to determine the flexural tensile strength of concrete with the addition of 2 and $3 \mathrm{~kg} / \mathrm{m}^{3}$ of synthetic fibers of different geometry and form. The following conclusions were drawn from the conducted research:

- As a result of adding synthetic fibers to concrete, the workability of the mixes deteriorated significantly. The consistency class decreased by three for FF_2, two for PM_3, PD_3 and PD_2, and one for PM_2, compared to plain concrete. Nevertheless, the 
type and fiber content did not significantly affect the compressive strength, which ranged from 58.06 to $61.31 \mathrm{MPa}$, depending on the mixture, while for concrete without fibers it was equal to $58.05 \mathrm{MPa}$.

- The fibers contributed to an increase in the flexural tensile strength of approximately 5.5\% for PM_3, PM_2, and PD_3; 11.5\% for PD_2 and 13.5\% for FF_2. The mixtures with slightly shorter fibers $\left(l_{\mathrm{f}}=48 \mathrm{~mm}\right)$ performed better, and in particular the one where a smaller amount of fibers $\left(2 \mathrm{~kg} / \mathrm{m}^{3}\right)$ has been used. However, the best results were obtained with a hybrid blend with $V_{f}=2 \mathrm{~kg} / \mathrm{m}^{3}$. This may be due to the fact that the combination of two types of fibers more effectively bridged the microcracks, and the lower fiber content allowed fibers for their more even distribution in the concrete.

- The damage of beams without fibers was brittle and sudden, unlike for the fiberreinforced concrete samples, which were still able to transfer a significant load with increasing crack mouth opening displacement, and possessed some ductility. The residual flexural tensile strengths of concrete with synthetic fibers usually reached higher values, when the fiber content was higher. Additionally, the mixture with the incorporation of the larger amount of fibers which were longer $\left(l_{f}=54 \mathrm{~mm}\right)$ performed best. It was because longer fibers more efficiently bridged the macrocracks. It is also worth noting that among the mixtures with $2 \mathrm{~kg} / \mathrm{m}^{3}$, the highest values for almost all residual strengths were achieved for the hybrid blend, which may indicate the positive effect of combining two different types of fibers.

- As a result of the addition of fibers to concrete, the fracture energy, calculated up to the crack mouth opening displacement of $3.5 \mathrm{~mm}$, increased from about 16 to 22 times depending on the type of the mixture.

- Significant dispersion of the force-crack mouth opening displacement curves was the result of a small fracture area (high statistical variability of the number of fibers crossing this surface) resulting from the used test method-according to EN 14651. Additionally, in the case of some mixtures, it was noticeable that some of the twisted fibers did not disintegrate, which resulted in the uneven distribution of fibers. The reason for large deviations in the results of individual samples may be connected with a different number of fibers in the cross-section of the crack.

- The formula proposed by the authors for calculating the flexural tensile strength for concrete with polymer fibers with a nominal fiber content of $\leq 1.0 \%$ and slenderness up to 200 correlates very well with the results of the presented studies, as well as with those contained in various literature positions. Regarding the formula proposed in the EN 14651 standard to determine the relationship between the deflection and the crack mouth opening displacement, it was concluded that it differs from the relationship recorded during the presented tests of beams with synthetic fibers. As a result, a new formula was proposed by the authors, together with equations describing crack mouth opening displacement-crack tip opening displacement and crack tip opening displacement-deflection dependencies.

- According to Model Code 2010, the use of 2 and $3 \mathrm{~kg} / \mathrm{m}^{3}$ of tested fibers in the concrete mix would not partially or fully replace traditional reinforcement in a form of steel bars. Furthermore, it was not possible to obtain $\sigma$-w curves from uniaxial tensile tests, and received results for maximum tensile strength did not show the clear influence of fibers' incorporation on concrete.

- The DIC technique can be successfully used to determine the crack mouth and crack tip opening displacements with very high accuracy.

Author Contributions: Conceptualization, Ł.D.; methodology, Ł.D. and J.B.; investigation, J.B.; data curation, J.B.; formal analysis, J.B., Ł.D. and P.W.; writing-original draft preparation, J.B.; writingreview and editing, Ł.D. and P.W.; visualization, J.B.; and supervision, Ł.D and P.W. All authors have read and agreed to the published version of the manuscript.

Funding: The research reported in this paper was co-financed by the Department of Building Structures at the Silesian University of Technology. 
Institutional Review Board Statement: Not applicable.

Informed Consent Statement: Not applicable.

Data Availability Statement: Not applicable.

Acknowledgments: The authors are deeply grateful to Astra Technologia Betonu and Visbud-Projekt for theirs help in conducting the experimental campaign and for financing and supporting this research.

Conflicts of Interest: The authors declare no conflict of interest. The funders had no role in the design of the study; in the collection, analyses, or interpretation of data; in the writing of the manuscript, or in the decision to publish the results.

\section{References}

1. Cajka, R.; Marcalikova, Z.; Kozielova, M.; Mateckova, P.; Sucharda, O. Experiments on Fiber Concrete Foundation Slabs in Interaction with the Subsoil. Sustainability 2020, 12, 3939. [CrossRef]

2. Sadowska-Buraczewska, B.; Szafraniec, M.; Barnat-Hunek, D.; Łagód, G. Flexural Behavior of Composite Concrete Slabs Made with Steel and Polypropylene Fibers Reinforced Concrete in the Compression Zone. Materials 2020, 13, 3616. [CrossRef]

3. Ferrara, L.; Meda, A. Relationships between fibre distribution, workability and the mechanical properties of SFRC applied to precast roof elements. Mater. Struct. 2006, 39, 411-420. [CrossRef]

4. Markovic, I. High-Performance Hybrid-Fibre Concrete; DUP Science DUP: Delft, The Netherlands, 2006; ISBN 9040726213.

5. Walraven, J.C. High performance fiber reinforced concrete: Progress in knowledge and design codes. Mater. Struct. 2009, 42, 1247-1260. [CrossRef]

6. Liao, L.; De La Fuente, A.; Cavalaro, S.H.P.; Aguado, A. Design procedure and experimental study on fibre reinforced concrete segmental rings for vertical shafts. Mater. Des. 2016, 92, 590-601. [CrossRef]

7. Ferdous, W.; Aravinthan, T.; Manalo, A.; Van Erp, G. Composite railway sleepers-New developments and opportunities. In Proceedings of the 11th International Heavy Haul Association Conference: Operational Excellence (IHHA 2015), Perth, Australia, 21-24 June 2015.

8. Ferdous, W.; Manalo, A.; Van Erp, G.; Aravinthan, T.; Kaewunruen, S.; Remennikov, A. Composite railway sleepers-Recent developments, challenges and future prospects. Compos. Struct. 2015, 134, 158-168. [CrossRef]

9. Aslani, F.; Nejadi, S. Self-compacting concrete incorporating steel and polypropylene fibers: Compressive and tensile strengths, moduli of elasticity and rupture, compressive stress-strain curve, and energy dissipated under compression. Compos. Part B Eng. 2013, 53, 121-133. [CrossRef]

10. Smarzewski, P. Effect of Curing Period on Properties of Steel and Polypropylene Fibre Reinforced Ultra-High Performance Concrete. IOP Conf. Ser. Mater. Sci. Eng. 2017, 245, 032059. [CrossRef]

11. Feng, J.; Sun, W.; Zhai, H.; Wang, L.; Dong, H.; Wu, Q. Experimental Study on Hybrid Effect Evaluation of Fiber Reinforced Concrete Subjected to Drop Weight Impacts. Materials 2018, 11, 2563. [CrossRef]

12. Mohajerani, A.; Hui, S.-Q.; Mirzababaei, M.; Arulrajah, A.; Horpibulsuk, S.; Kadir, A.A.; Rahman, T.; Maghool, F. Amazing Types, Properties, and Applications of Fibres in Construction Materials. Materials 2019, 12, 2513. [CrossRef] [PubMed]

13. Glinicki, M.A. Testing of macro-fibres reinforced concrete for industrial floors. Cem. Wapno Beton 2008, 13, 184-195.

14. Blazy, J.; Blazy, R. Polypropylene fiber reinforced concrete and its application in creating architectural forms of public spaces. Case Stud. Constr. Mater. 2021, 14, e00549. [CrossRef]

15. Mohammadhosseini, H.; Alrshoudi, F.; Tahir, M.M.; Alyousef, R.; Alghamdi, H.; Alharbi, Y.R.; Alsaif, A. Durability and thermal properties of prepacked aggregate concrete reinforced with waste polypropylene fibers. J. Build. Eng. 2020, 32, 101723. [CrossRef]

16. Richardson, A. Polypropylene fibres in concrete with regard to durability. Struct. Surv. 2003, 21, 87-94. [CrossRef]

17. Rashid, M.U. Experimental investigation on durability characteristics of steel and polypropylene fiber reinforced concrete exposed to natural weathering action. Constr. Build. Mater. 2020, 250, 118910. [CrossRef]

18. Manalo, A.; Maranan, G.; Benmokrane, B.; Cousin, P.; Alajarmeh, O.; Ferdous, W.; Liang, R.; Hota, G. Comparative durability of GFRP composite reinforcing bars in concrete and in simulated concrete environments. Cem. Concr. Compos. 2020, $109,103564$. [CrossRef]

19. Bošnjak, J.; Sharma, A.; Grauf, K. Mechanical Properties of Concrete with Steel and Polypropylene Fibres at Elevated Temperatures. Fibers 2019, 7, 9. [CrossRef]

20. EN 14889-2:2007. Fibres for Concrete-Part 2: Polymer Fibres_Definitions, Specifications and Conformity; European Committee for Standardization: Brussels, Belgium, 2007.

21. Ma, K.; Qi, T.; Liu, H.; Wang, H. Shear Behavior of Hybrid Fiber Reinforced Concrete Deep Beams. Materials 2018, 11, 2023. [CrossRef]

22. He, J.; Chen, W.; Zhang, B.; Yu, J.; Liu, H. The Mechanical Properties and Damage Evolution of UHPC Reinforced with Glass Fibers and High-Performance Polypropylene Fibers. Materials 2021, 14, 2455. [CrossRef] [PubMed]

23. Guerini, V.; Conforti, A.; Plizzari, G.; Kawashima, S. Influence of Steel and Macro-Synthetic Fibers on Concrete Properties. Fibers 2018, 6, 47. [CrossRef] 
24. Lofgren, I.; Stang, H.; Olesen, J.F. The WST method, a fracture mechanics test method for FRC. Mater. Struct. 2007, 41, 197-211. [CrossRef]

25. Skoček, J.; Stang, H. Inverse analysis of the wedge-splitting test. Eng. Fract. Mech. 2008, 75, 3173-3188. [CrossRef]

26. International Federation for Structural Concrete Model Code 2010, Final draft. Struct. Concr. 2013, 14, 10-18.

27. Louch, K.; Day, R.; Hulett, T.; Woods, N.; Eddy, D.; Simpson, D. Technical Report Concrete Industrial Ground Floors. A Guide to Design and Construction, 4th ed.; The Concrete Society: Camberley, UK, 2016; Volume 29, ISBN 9781904482772.

28. EN 14651+A1:2007. Test Method for Metallic Fibre Concrete-Measuring the Flexural Tensile Strength (Limit of Proportionality (LOP), Residual); European Committee for Standardization: Brussels, Belgium, 2007.

29. Babski, V.; Hüsken, G.; Pirskawetz, S.; Ehlers, N.; Kühne, H.-C.; Brouwers, H.J.H. Characterisation of Ultra-High Performance Fibre Reinforced Concrete (UHPFC) under Tensile Loading by Acoustic Emission and Optical Deformation Analysis. In Proceedings of the Hipermat 2016 - 4th International Symposium on Ultra-High Performance Concrete and High Performance Construction Materials, Kassel, Germany, 9-11 March 2016; pp. 1-9.

30. Skarżyński, L.; Suchorzewski, J. Mechanical and fracture properties of concrete reinforced with recycled and industrial steel fibers using Digital Image Correlation technique and X-ray micro computed tomography. Constr. Build. Mater. 2018, 183, 283-299. [CrossRef]

31. Wu, Z.; Rong, H.; Zheng, J.; Xu, F.; Dong, W. An experimental investigation on the FPZ properties in concrete using digital image correlation technique. Eng. Fract. Mech. 2011, 78, 2978-2990. [CrossRef]

32. Alam, S.Y.; Saliba, J.; Loukili, A. Fracture examination in concrete through combined digital image correlation and acoustic emission techniques. Constr. Build. Mater. 2014, 69, 232-242. [CrossRef]

33. Manning, M.P.; Weldon, B.D.; McGinnis, M.J.; Jauregui, D.V.; Newtson, C.M. Locally developed Ultra-High Performance Concrete: Behaviour Analysis of prestressed Channel Girders. In Proceedings of the Hipermat 2016-4th International Symposium on Ultra-High Performance Concrete and High Performance Construction Materials, Kassel, Germany, 8-11 March 2016; pp. 1-9.

34. Randl, N.; Mészöly, T.; Harsányi, P. Load Bearing Behaviour of slender UHPC Beam Members in Shear. In Proceedings of the Hipermat 2016 - 4th International Symposium on Ultra-High Performance Concrete and High Performance Construction Materials, Kassel, Germany, 8-11 March 2016; pp. 1-8.

35. Shih, M.-H.; Sung, W.-P. Application of digital image correlation method for analysing crack variation of reinforced concrete beams. Sadhana 2013, 38, 723-741. [CrossRef]

36. Tsangouri, E.; Aggelis, D.G.; Van Tittelboom, K.; De Belie, N.; Van Hemelrijck, D. Detecting the Activation of a Self-Healing Mechanism in Concrete by Acoustic Emission and Digital Image Correlation. Sci. World J. 2013, 2013, 1-10. [CrossRef]

37. Aggelis, D.; Verbruggen, S.; Tsangouri, E.; Tysmans, T.; Van Hemelrijck, D. Characterization of mechanical performance of concrete beams with external reinforcement by acoustic emission and digital image correlation. Constr. Build. Mater. 2013, 47, 1037-1045. [CrossRef]

38. Srikar, G.; Anand, G.; Prakash, S.S. A Study on Residual Compression Behavior of Structural Fiber Reinforced Concrete Exposed to Moderate Temperature Using Digital Image Correlation. Int. J. Concr. Struct. Mater. 2016, 10, 75-85. [CrossRef]

39. Bertelsen, I.; Ottosen, L.M.; Fischer, G. Quantitative analysis of the influence of synthetic fibres on plastic shrinkage cracking using digital image correlation. Constr. Build. Mater. 2018, 199, 124-137. [CrossRef]

40. Rucka, M.; Wojtczak, E.; Knak, M.; Kurpińska, M. Characterization of fracture process in polyolefin fibre-reinforced concrete using ultrasonic waves and digital image correlation. Constr. Build. Mater. 2021, 280, 122522. [CrossRef]

41. Bhosale, A.B.; Prakash, S.S. Crack Propagation Analysis of Synthetic vs. Steel vs. Hybrid Fibre-Reinforced Concrete Beams Using Digital Image Correlation Technique. Int. J. Concr. Struct. Mater. 2020, 14, 1-19. [CrossRef]

42. Legeron, F.; Paultre, P. Prediction of modulus of rupture of concrete. ACI Mater. J. 2000, 97, 193-200.

43. Glinicki, M.A. Concrete with structural reinforcement. In Proceedings of the XXV Polish Workshop of Structural Designer Work, Szczyrk, Poland, 10-13 March 2010; pp. 279-308. (In Polish).

44. Glinicki, M.A. Assessment and design of fibre reinforced concrete based on residual strength. Roads Bridges 2002, 5-36. (In Polish)

45. Swamy, R.; Mangat, P. Influence of fiber geometry on the properties of steel fiber reinforced concrete. Cem. Concr. Res. 1974, 4, 451-465. [CrossRef]

46. Carlesso, D.M.; Cavalaro, S.; de la Fuente, A. Flexural fatigue of pre-cracked plastic fibre reinforced concrete: Experimental study and numerical modeling. Cem. Concr. Compos. 2021, 115, 103850. [CrossRef]

47. Camille, C.; Hewage, D.K.; Mirza, O.; Mashiri, F.; Kirkland, B.; Clarke, T. Performance behaviour of macro-synthetic fibre reinforced concrete subjected to static and dynamic loadings for sleeper applications. Constr. Build. Mater. 2021, $270,121469$. [CrossRef]

48. Soltanzadeh, F.; Cunha, V.; Barros, J. Assessment of different methods for characterization and simulation of post-cracking behavior of self-compacting steel fiber reinforced concrete. Constr. Build. Mater. 2019, 227, 116704. [CrossRef]

49. ASTM C1018-94. Standard Test Method for Flexural Toughness and First-Crack Strength of Fiber-Reinforced Concrete (Using Beam with Third-Point Loading); ASTM International: West Conshohocken, PA, USA, 1994.

50. Chajec, A.; Sadowski, L. The Effect of Steel and Polypropylene Fibers on the Properties of Horizontally Formed Concrete. Materials 2020, 13, 5827. [CrossRef] [PubMed] 
51. Hussain, I.; Ali, B.; Akhtar, T.; Jameel, M.S.; Raza, S.S. Comparison of mechanical properties of concrete and design thickness of pavement with different types of fiber-reinforcements (steel, glass, and polypropylene). Case Stud. Constr. Mater. 2020, 13, e00429. [CrossRef]

52. Ahmed, T.W.; Ali, A.A.M.; Zidan, R.S. Properties of high strength polypropylene fiber concrete containing recycled aggregate. Constr. Build. Mater. 2020, 241, 118010. [CrossRef]

53. Hongbo, Z.; Haiyun, Z.; Hongxiang, G. Characteristics of ductility enhancement of concrete by a macro polypropylene fiber. Results Mater. 2020, 100087. [CrossRef]

54. Liang, N.; Dai, J.; Liu, X. Study on Tensile Damage Constitutive Model for Multiscale Polypropylene Fiber Concrete. Adv. Mater. Sci. Eng. 2016, 2016, 1-6. [CrossRef]

55. Banthia, N.; Moncef, A.; Chokri, K.; Sheng, J. Uniaxial tensile response of microfibre reinforced cement composites. Mater. Struct. 1995, 28, 507-517. [CrossRef]

56. Abrishambaf, A.; Pimentel, M.; Nunes, S. Influence of fibre orientation on the tensile behaviour of ultra-high performance fibre reinforced cementitious composites. Cem. Concr. Res. 2017, 97, 28-40. [CrossRef]

57. EN 197-1:2012. Cement-Part 1: Composition, Specifications and Conformity Criteria for Common Cements; European Committee for Standardization: Brussels, Belgium, 2012.

58. EN 12350-2:2019-07. Testing Fresh Concrete_Part 2: Slump Test; European Committee for Standardization: Brussels, Belgium, 2019.

59. EN 12350-8:2012. Testing Fresh Concrete-Part 8: Self-Compacting Concete—Slump-Flow Test; European Committee for Standardization: Brussels, Belgium, 2012.

60. EN 206:2013+A1:2016. Concrete. Specification, Performance, Production and Conformity; European Committee for Standardization: Brussels, Belgium, 2016.

61. El-Newihy, A.; Azarsa, P.; Gupta, R.; Biparva, A. Effect of Polypropylene Fibers on Self-Healing and Dynamic Modulus of Elasticity Recovery of Fiber Reinforced Concrete. Fibers 2018, 6, 9. [CrossRef]

62. EN 12390-2:2019. Testing Hardened Concrete-Part 2: Making and Curing Specimens for Strength Tests; European Committee for Standardization: Brussels, Belgium, 2019.

63. Fantilli, A.P.; Kwon, S.; Mihashi, H.; Nishiwaki, T. Synergy assessment in hybrid Ultra-High Performance Fiber-Reinforced Concrete (UHP-FRC). Cem. Concr. Compos. 2018, 86, 19-29. [CrossRef]

64. Park, G.-K.; Park, G.-J.; Park, J.-J.; Lee, N.; Kim, S.-W. Residual Tensile Properties and Explosive Spalling of High-Performance Fiber-Reinforced Cementitious Composites Exposed to Thermal Damage. Materials 2021, 14, 1608. [CrossRef] [PubMed]

65. Behfarnia, K.; Behravan, A. Application of high performance polypropylene fibers in concrete lining of water tunnels. Mater. Des. 2014, 55, 274-279. [CrossRef]

66. Yin, S.; Tuladhar, R.; Shi, F.; Combe, M.; Collister, T.; Sivakugan, N. Use of macro plastic fibres in concrete: A review. Constr. Build. Mater. 2015, 93, 180-188. [CrossRef]

67. Li, D.; Liu, S. Macro polypropylene fiber influences on crack geometry and water permeability of concrete. Constr. Build. Mater. 2019, 231, 117128. [CrossRef]

68. Hsie, M.; Tu, C.; Song, P. Mechanical properties of polypropylene hybrid fiber-reinforced concrete. Mater. Sci. Eng. A 2008, 494, 153-157. [CrossRef]

69. Ortiz, M.A.; Jj, S.; De Luna, A.M.; Ángel, J.; Lozano, O.; Jaime, L.P.; Martínez, J.P.; José, J.; Bernal, S.; Flores, J.A. Experimental mechanical characterization of steel and polypropylene fiber reinforced concrete. Rev. Técnica Fac. Ing. Univ. Zulia 2014, 37, 106-115. [CrossRef]

70. Ibrahim, M.H.W.; Mangi, S.A.; Burhanudin, M.K.; Ridzuan, M.B.; Jamaluddin, N.; Shahidan, S.; Wong, Y.; Faisal, S.; Fadzil, M.A.; Ramadhansyah, P.J.; et al. Compressive and flexural strength of concrete containing palm oil biomass clinker and polypropylene fibres. IOP Conf. Ser. Mater. Sci. Eng. 2017, 271, 12011. [CrossRef]

71. Li, J.; Niu, J.; Wan, C.; Liu, X.; Jin, Z. Comparison of flexural property between high performance polypropylene fiber reinforced lightweight aggregate concrete and steel fiber reinforced lightweight aggregate concrete. Constr. Build. Mater. 2017, 157, 729-736. [CrossRef]

72. Altalabani, D.; Bzeni, D.K.; Linsel, S. Mechanical properties and load deflection relationship of polypropylene fiber reinforced self-compacting lightweight concrete. Constr. Build. Mater. 2020, 252, 119084. [CrossRef]

73. Roesler, J.R.; Lange, D.A.; Altoubat, S.A.; Rieder, K.-A.; Ulreich, G.R. Fracture of Plain and Fiber-Reinforced Concrete Slabs under Monotonic Loading. J. Mater. Civ. Eng. 2004, 16, 452-460. [CrossRef]

74. Shi, F.; Pham, T.M.; Hao, H.; Hao, Y. Post-cracking behaviour of basalt and macro polypropylene hybrid fibre reinforced concrete with different compressive strengths. Constr. Build. Mater. 2020, 262, 120108. [CrossRef]

75. Alberti, M.G.; Enfedaque, A.; Gálvez, J.C. Polyolefin Fibres for the Reinforcement of Concrete; IntechOpen: London, UK, 2017.

76. Buratti, N.; Mazzotti, C.; Savoia, M. Post-cracking behaviour of steel and macro-synthetic fibre-reinforced concretes. Constr. Build. Mater. 2011, 25, 2713-2722. [CrossRef]

77. Soutsos, M.; Le, T.; Lampropoulos, A. Flexural performance of fibre reinforced concrete made with steel and synthetic fibres. Constr. Build. Mater. 2012, 36, 704-710. [CrossRef]

78. Singh, N.K.; Rai, B. A Review of Fiber Synergy in Hybrid Fiber Reinforced Concrete. J. Appl. Eng. Sci. 2018, 8, 41-50. [CrossRef]

79. Ismail, S.; Ramli, M. Effects of Adding Fibre on Strength and Permeability of Recycled Aggregate Concrete Containing Treated Coarse RCA. International J. Civ. Environ. Eng. 2014, 8, 918-924. 
80. Sivakumar, A.; Santhanam, M. Mechanical properties of high strength concrete reinforced with metallic and non-metallic fibres. Cem. Concr. Compos. 2007, 29, 603-608. [CrossRef]

81. Altoubat, S.A.; Roesler, J.R.; Lange, D.A.; Rieder, K.-A. Simplified method for concrete pavement design with discrete structural fibers. Constr. Build. Mater. 2008, 22, 384-393. [CrossRef]

82. Leong, G.W.; Mo, K.H.; Loh, Z.P.; Ibrahim, Z. Mechanical properties and drying shrinkage of lightweight cementitious composite incorporating perlite microspheres and polypropylene fibers. Constr. Build. Mater. 2020, 246, 118410. [CrossRef]

83. Guo, H.; Jiang, L.; Tao, J.; Chen, Y.; Zheng, Z.; Jia, B. Influence of a hybrid combination of steel and polypropylene fibers on concrete toughness. Constr. Build. Mater. 2021, 275, 122132. [CrossRef] 